\title{
El Congo a partir de Mobutu
}

R I C H A R D G O T T es profesor-investigador sobre asuntos de Africa y el Medio Oriente en el Instituto de Estudios Internacionales y Director de Estudios Internacionales.

Durante varios años fue investigador del Royal Institute of International Affairs de Londres. Entre sus publicaciones más importantes está The Appeasers, sobre la polfitica exterior británica antes de Munich, de la que es coautor.

Hacia fines de cada año, con monótona regularidad, el Congo pasa a ocupar los titulares de la prensa internacional. El 24 de noviembre de 1964, fueron los paracaidistas belgas en Stanleyville -una operación internacional que incluyó aviones norteamericanos y una base británica (la isla Ascensión). El 25 de noviembre de 1965, Joseph Mobutu derrocó a Moise Tshombe, dando lugar a una nueva era en los asuntos congoleses. Luego, hacia fines de 1966, después de un año de espasmódicas rebeliones, subrayadas por la ejecución pública de cuatro ministros del régimen anterior, incluyendo al Primer Ministro de Tshombe, Evariste Kimba, el Presidente Mobutu procedió a provocar un enfrentamiento con la Unión Minera.

De hecho, los acontecimientos del Congo, bastante complicados durante el período inmediato de postindependencia, incluida la intervención de las Naciones Unidas, han llegado a ser aún más complejos en los años posteriores a la retirada de las Naciones Unidas, julio de 1964. Sin embargo, de la aparente anarquía, más confusa aún debido a las informaciones contradictorias de prensa, pueden aislarse ciertos acontecimientos cuya significación sobrepasa los marcos puramente locales. El factor dominante en la historia del Congo, desde su independencia, ha sido la intervención extranjera, y la naturaleza de dicha intervención es siempre cambiante. Cada cambio se ve, inevitablemente, reflejado en los asuntos internos del Congo. Catherine Hoskyns, historiadora de la intervención de las Naciones Unidas en el Congo, ha caracterizado el problema como sigue, según escribe a comienzos de 1965:

"La paradoja fundamental tras la totalidad de los problemas del Congo, pasados y presentes, reside, por una parte, en que el tipo de gobịerno que el Congo elogiría libremente estaría demasiado 
inclinado a la izquierda, cosa en cierta medida inaceptable para las Potencias Occidentales (quienes aún tienen importantes intereses, tanto estratégicos como económicos, en el Congo); y, por otra, en que el tipo de gobierno considerado aceptablé por las Potencias Occidentales, es incapaz de despertar el apoyo popular suficiente para unificar y gobernar el pais"1.

A continuación, Miss Hoskyns sugiere que el Congo podría encontrar estabilidad permanente sólo en cuanto fuera capaz de resolver dicha paradoja. En esta ocasión intentaré demostrar, aunque de manera insatisfactoria, que dicha paradoja ha sido resuelta y que, bajo el gobierno derechista del Presidente Mobutu, se ha logrado cierto grado de relativa estabilidad. No es en sí mismo un régimen atrayente $y$, desde el punto de vista de las represiones internas, no se compara favorablemente con otras dictaduras semejantes. Pero aun en Europa, si incluimos en ella a Turquía, la ejecución de un primer ministro no constituye un hecho desconocido y el salvajismo congolés tampoco puede calificarse de típicamente africano. Dejando de lado el problema moral, hay bastante evidencia en cuanto a que si se trata de estabilidad para el Congo, ésta ha sido lograda. Por esto, el golpe de estado del general Mobutu, en noviembre de 1965, puede ser juzgado, no ya como un incidente más en el interminable cambio entre Kasavubu, Tshombe y Mobutu, sino como la inauguración de una nueva era.

En 1966, hubo muchos momentos en que esto pudo parecer un juicio aventurado. En agosto de ese año, un corresponsal en Kinshasa (Leopoldville) del Washington Evening Star, comentaba, poco después del estallido del motín de los ex gendarmes katangueses en Kisangani (Stanleyville), que "lo único en que prácțicamente todo el mundo está de acuerdo aquí, sean congoleses o extranjeros, es que el general Mobutu está viviendo sus 'descuentos' "2.

Richard Hall, el tradicionalmente bien informado corresponsal del Guardian y del Observer, emitió un juicio similar, en los momentos en que se planteaba la crisis con la Unión Minera. El prestigio de Mo= butu, señalo, "ya comienza derrumbarse"s. Sin embargo, la consolidación de la posición interna de Mobutu durante el año 1966 y el reconocimiento internacional que ha obtenido parecen indicar que, descontados los accidentes, el Presidente está allí para quedarse.

'Catherine Hoskyns, "The Tshombe Regime", The World Today, febrero 1965.

"Clayton Fritchey, "Mobutu Living on Borrowed Time", Washinglon Evening Slar, 20 agos1966.

Observer, 15 enero 1967. 
La estabilidad política es una expresión usualmente aplicada a los países ricos de la Europa occidental, los paises blancos de la Commonwealth y Norteamerica. Por esta razón puede parecer apresurado y hasta atrevido aplicarla en conexión con cualquier región del tercer mundo, y mucho menos al Congo. Sin embargo, si un régimen estable puede ser definido, tal como el diccionario lo indica, como "firmemente asentado o establecido, difícil de ser movido, cambiado o destruido", entonces de acuerdo a mi punto de vista el Congo de Mobutu cabe en esta definición. Este es un juicio audaz, que se basa en la firme creencia que Mobutu está creando un nuevo Congo que no será otro peón más en el juego internacional de las grandes potencias. Al gunos años atrás, en las calles de La Habana, carteles exhibían la última fotografía del desaparecido Patrice Lumumba, capturado, con sus manos atadas a la espalda. El texto de la fotografía orgullosamente anunciaba "Cuba no es el Congo". La conciencia de que pequeños o grandes países pueden dividir o armar querellas contra los grandes poderes persiste, pero la afirmación del nacionalismo es el único acto político que pone fin a la interferencia externa. En este sentido el Congo de Mobutu no es tampoco el Congo.

Uno de los principales problemas al intentarse la interpretación del panorama congoles, ha sido siempre el de tratar de identificar cuál es la potencia extranjera, entre las muchas que alli intervienen, que de hecho se beneficia con su intervención. Entre los sectores de izquierda se presume habitualmente que el Oeste es monolítico y que opera con mínimas disensiones, pero con la mirada fija sobre su principal objetivo: el mantenimiento eficiente del régimen capitalista en medio de condiciones siempre cambiantes. En este sentido se expresa Roger Murray, en un aŕtículo excepcionalmente interesante titulado "Militarismo en Africa":

"El hecho es que las estructuras político-institucionales del Congo-Leopoldville y de la Federación Nigeriana eran incompatibles aun con los más mínimos elementos de racionalidad y eficiencia burguesas, lo que constituía un impedimento para las formas contemporáneas de operación capitalista (como oposición a enclaves extractivos). En Nigeria, la coalición de una pandilla polftica y burocrático-feudal, cuya dominación se basaba en la coerción y en el soborno; en el Congo, una situación de permanente guerra civil, ausencia de efectiva autoridad civil, atrofia de la producción (excepto en el sector minero), y disgregación del mercado interno; en ambos estados, la autonomía provincial y la descentralización proporcionaban el maxco politico-legal para el derroche masivo de re- 
cursos a través de agencias económicas y 'presupuestos' locales; en ambos estados, esta situación fue progresivamente sentida como un impedimento, tanto por los capitalistas nacionales como por los extranjeros.

"De ahí la tendencia, aparecida después de los golpes de estado, hacia una descentralización del poder y la eliminación o reducción de las provincias (con sus respectivos atributos fiscales y económicos), sumada a los esfuerzos para proporcionar condiciones políticas más propicias para la explotación capitalista y el desarrollo. Desde hace tiempo es notorio que Nigeria y el Congo -gracias a sus considerables recursos y mercados internos potenciales- son, con mucho, los estados africanos independientes más significativos desde el punto de vista económico.

"Las relaciones entre Bélgica y el régimen congolés se han deteriorado en forma relativamente rápida, luego de la luna de miel inicial. Violentas disputas han sido planteadas respecto de la cartera de inversiones del Gobierno congolés, de los estatutos de SABENA Y OTRACo, del lugar de residencia legal de los principales trusts belgas que operan en el Congo (circunstancia importante en relación a aspectos tributarios y de control de la política de la compañia) , y de las actividades de Tshombe en Bruselas. Estos contratiempos y algunos ajustes a favor de los intereses congoleños no deben sorprender ni inducir a engaño. De hecho, Mobutu es representativo del tipo de hombre fuerte contrarrevolucionario con ciertos tintes antimperialistas; es la antítesis exacta de Tshombe, civil y europeizante hasta la médula de los huesos"4.

Este análisis continúa una añtigua tradición al escribir sobre el Congo. Durante los primeros años en que tuviera lugar la intervención de las Naciones Unidas, era costumbre agrupar a las potencias occidentales como si tuvieran un interés conjunto en sostener a un político, o partido político, en particular. Desde luego que, en 1960, fue muy notoria la general tolerancia occidental hacia Tshombe, paralela al disgusto que en esos sectores despertaba Lumumba, pero, aun después de terminada la secesión de Katanga, se mantuvo la tendencia entre los observadores a dar por sentado que las diferentes potencias occidentales tenían básicamente los mismos intereses en el Congo. En esa época, Conor Cruise O'Brien decía a sus auditores en el Makerere University College, el 15 de julio de 1964:

"Los círculos políticos en Leopoldville, purgados, corrompidos e intimidados, devinieron más representativos de las opiniones ex-

‘Roger Murray, "Militarism in Africa", New Left Review, julio-agosto 1966. 
presadas en las salas de directorio de empresas en Bruselas, Londres, París y Nueva York, que de cualquier real corriente de opinión en el Congo. Fue asi como Tshombe, el comprobado amigo de esos directorios, pasó a ser Primer Ministro del Congo"`.

Sin embargo, por mucho que los directorios internacionales desearon traslaclar a Tshombe de Katanga a Leopoldville -deseo, por lo demás, milagrosamente realizado en julio de 1961- resultó mucho más difícil mantenerlo allí. Una vez que Tshombe estuvo de hecho a cargo del gobierno central, pasaron a estar comprometidos los intereses de estado de las potencias occidentales, y no sólo los aspectos financieros: Inevitablemente, y en gran parte debido a la diferente evaluación de la situación interna en el Congo, dichos intereses entraron en conflicto. Se daba la historia, vieja en Africa, del conflicto entre los Estados Unidos y sus aliados europẹos - las potencias coloniales en Africa- sobre lo que sería el futuro esquema del Africa. La política norteamericana en Africa llevó a profundos desacuerdos entre Estados Unidos y Gran Bretaña, Francia y Bélgica, tanto bajo Eisenhower como en la administración de Kennedy, y, por supuesto, los Estados Unidos enfrentaron a Folanda acerca del futuro de la Nueva Guinea Holandesa. Difícilmente el Congo podía ser una excepción. De ahí que la llegacla de Tshombe como Primer Ministro del Congo en julio de 1964 exacerbara las tensiones existentes dentro de la alianza occidental. En términos generales, Portugal y Bélgica aprobaron a Tshombe; Bélgica, porque lo aprobaba la Unión Minera; Portugal, porque, al parecer, se demostraría hostil hacia los movimientos de liberación angoleses, los que usaban al Congo como base para sus ataques a las provincias del norte de Angola. Ante la inminente independencia de Zambia, nación abiertamente hostil al colonialismo portugués, este último debió enfrentar las perspectivas de tener dos extensas fronteras con enemigos potenciales, experiencia ésta que el resto de los estados sudafricanos gobernados por una supremacía blanca había logrado evitar.

Los Estados Unidos, sin embargo, a pesar de su clara conciencia de los beneficios obteniclos por la Unión Minera y Bélgica, derivados de sus intereses en el Congo, se vieron determinados a evaluar la totalidad de la situación en una perspectiva más amplia.

En una serie de interesantes artículos publicados por Le Monde, en enero de 1967, titulados "Los Estados Unidos en busca de una política africana", Philippe Decraene intentó describir los principios que configuran la política exterior norteamericana en Africa:

sConor Cruisc O'Brien, "The UN, Congo and Tshombe", Transition, julio-agosto 1966. 
"El más importante de estos principios, y tal vez también el más nuevo, es aquel según el cual el gobierno norteamericano no debe tratar de sustituir a las antiguas potencias coloniales, sino completar su propia acción.

"Solamente en la medida o riesgo que se cree un vacío político es que los norteamericanos se deciden a llenarlo. En nombre de esos principios, los dirigentes de Washington se decidieron a comprometerse militar y políticamente en los asuntos congoleses. Contrariamente a la idea más divulgada, los Estados Unidos intervinieron en la lucha entre los gobiernos de Leopoldville y los secesionistas de Elisabethville y luego entre el poder central y los rebeldes, no a nombre de imperativos económicos; es cierto que el grupo Rockefeller tiene intereses en la Tanganyika Concession, la que a su vez controlaba, hasta hace poco, a la Unión Minera del Alto Katanga; sin embargo, el conjunto de las inversiones norteamericanas en el Congo represența 20 millones de dólares, mientras que las inversiones belgas superan en ese país los dos mil millones de dólares" ".

Desde el punto de vista de Occidente (a través de los ojos de Estados Unidos), las ventajas positivas de la posición estratégica y económica del Congo son mínimas. El Oeste podría, en una emergencia, prescindir de las utilidades del cobre; tampoco necesita bases milita-. res. Pero bajo circunstancia alguna podría permitir que el Congo cayera en manos comunistas - se trate de la variedad soviética o de la. china-, o de nacionalistas de izquierda, simpatizantes de Moscú, Pekín (o La Habana). De acuerdo a este argumento, es preferible que el Congo caiga nuevamente en el caos y la anarquía -posición en que puede ser neutralizado con efectividad-, a que la izquierda se haga cargo del país. De ahí que los Estados Unidos, aun cuando no tiene prejuicios en contra de Tshombe, no estaba preparado para apoyarlo si éste no lograba suficiente apoyo interno y externo. Dada su carrera anterior, esto último era, en el mejor de los casos, inseguro. Tshombe contaba con partidarios en algunas regiones del Congo, pero, aun en el supuesto de una amplia popularidad en todas las provincias, para los nacionalistas africanos continuaría siendo inaceptable.

Sin embargo, la situación durante el período en que Tshombe fue Primer Ministro no fue tan definidamente blanca o negra, como podría inferirse del análisis anterior. Los belgas no estuvieron nunca ciento por cientó tras él, y los Estados Unidos durante un tiempo le concedieron el beneficio de la duda. Gatherine Hoskyns, al escribir

-Philippe Decracne, "Les Etats-Unis a la recherche d'une politique africaine", Le Monde, 4, 5, 6, enero 1967 . 
alrededor de seis semanas después de las operaciones conjuntas anglobelga-americanas sobre Stanleyville, evalúa de la siguiente manera las diferentes posiciones:

"El gobierno belga que, al menos en 1960, respaldaba con firmeza a Tshombe, aparece manteniéndolo hoy claramente a distancia, y ciertos políticos belgas no se han tomado mayores molestias para disimular su preferencia por casi cualquier persona en el poder en el Congo, en lugar de Tshombe. Los norteamericanos, por otra parte, que en 1961-62, llegaron muy lejos en su afán de destruir el poder de Tshombe en Katanga, hoy le dan importante respaldo moral y material. Pero incluso los norteamericanos han dejado en claro que lo respaldan a falta de alguien mejor, y si apareciera cualquier otro líder capaz de realizar el mismo trabajo, dejarian de lado con alivio a su actual protegido" 7 .

Nueve meses más tarde, casi hecho a la medida, el general Mobutu se hizo cargo del poder en Leopoldville, despidiendo no sólo al Primer Ministro Tshombe, sino también al Presidente Kasavubu. Aun cuando la reacción inicial belga fue favorable, el más somero análisis de los antecedentes de Mobutu permitía suponer que el hecho sincronizaba mejor con la interpretación norteamericana de lo que era necesario para Africa, a saber, una estabilidad pro occidental que no ofreciera posibilidad alguna para que grupos izquierdistas o revolucionarios permitieran la entrada de China o la Unión Soviética al continente africano. No era necesario suponer que Mobutu era el designado por la Ofícina Central de Inteligencia (CIA), aun cuando siempre se ha pensado que la CIA algo tuvo que ver con los inicios de su ascensión al poder, en 1960 (Andrew Tully, en su libro Cia: la historia por dentro, sostiene que Mobutu fue descubierto y apoyado por la CIA). Más importante es el thecho de que Mobutu, como jefe de las fuerzas armadas, tenía bajo su control las enormes cantidades de nueva ayuda militar norteamericana llegada al país, la que, en 1965, excedía considerablemente, en proporción de casi cuatro a uno, a aquella entregada por los belgas. El hombre que aseguraba el pago a las fuerzas armadas, tanto en 1965, como en 1960, estaba destinado a emerger como el hombre fuerte del país. Respecto del golpe de Mobutu en 1960, Catherine Hoskyns hace los siguientes comentarios en su libro:

"cualquiera que fuera su intención, la actitud de las Naciones Unidas al pagar a las tropas de Leopoldville, el 10 de septiembre, sig-

'Catherine Hoskyns, ver nota 1. 
nificó un paso muy avanzado en el reforzamiento de la autoridad de Mobutu, al hacer posible el golpe"8.

Conor Gruise O'Brien agrega en su comentario acerca del libro de Miss Hoskyns:

"Mobutu disponia de autoridad militar en la medida que pudiera obtener que alguien pagara sus tropas",

Es significativo que la más crucial de las rebeliones en contra de Mobutu, en 1966, ocurriera en Kisangani (Stanleyville) a raíz de que los soldados reclamaron por no recibir su paiga.

Dada la fragmentación de los partidos políticos y la endémica insatisfacción tribal, fue casi inevitable la decisión norteamericana de respaldar al hombre que controlaba al ejército -considerando además que los Estados Uniclos deseaban asegurar que el Congo no volvería a irrumpir en el escenario internacional. En ausencia de una alternativa lumumbista - la que se ha transformado prácticamente en una causa perdida descle fines de 1965, incluso para aquellos a quienes favorecía y que creían que no habría reconciliación en el Congo sin la participación del Movimiento Lumumbista Nacional Congolés- era obvia la elección del ejército como el único instrumento capaz de forjar la unidad nacional.

En los hechos, el régimen de Mobutu recibió el apoyo del MNC, ahora dirigido por Antoine Kiwewa, el 21 de diciembre de 1965. Durante el año siguiente, Mobutu volvería a demostrar una y otra vez que intentaba asegurar que el sentimiento pro lumumbista se enraizaba fuertemente tras él. El .30 de junio de 1966, sexto aniversario de la independencia del Congo, Mobutu proclamó a Lumumba como héroe nacional que entregara su vida no sólo en aras de la independencia política del Congo, sino que además (lo que es más importante aún desde el punto de vista de Mobutu) porque habia intentado lograr la independencia económica. Esta desconcertante declaración, de labios del hombre a cargo del ejército que arrestara a Lumumba en 1960 , fue hecha ante los Presidentes Nyerere y Kaunda. En diciembre de 1966 se tomaron nuevas medidas en pro de la santificación del líder muerto, al anunciar Mobutu que la casa en Elisabethville, donde ha-

\footnotetext{
"Catherine Hoskyns, "The Congo since Independence", p. 216, Oxford University Press, 1965. "Conor Cruise O'Brien, "The Congo, the United Nations, and Chatham House", New Lejt Review, mayo-junio 1955.
} 
bía sido asesinado Lumumba, pasaba a ser lugar de peregrinaje nacional ${ }^{10}$.

Aun antes que este rasgo pro lumumbista fuera notorio, hecho que sin duda alguna provocó una inmediata respuesta en gran número de estados africanos independientes, Mobutu había iniciado los movimientos necesarios para conseguir el reconocimiento africano para su régimen. Este fue reconocido, poco tiempo después que el golpe tuviera lugar, por Burundi, Chad, Ghana, Nigeria, Senegal, Togo y Zambia; en este sentido debe recordarse que esa lista incluye la Ghana de Nkrumah, quien no tenía razones para querer a Mobutu (durante ol período en que Mobutu fue Primer Ministro, éste expulsó a los diplomáticos de Ghana de Leopoldville, en noviembre de 1960). Subsiguientemente, a mediados de 1966, el Gobierno del Congo anunció su intención cle abrir embajadas en la República Centroafricana (bajo nueva administración desde el primero de enero de 1966, cuando el comandante en jefe, coronel Jean Bedel Bokasa tomó el poder de manos del Presidente David Dacko), Uganda y el Sudán. Tampoco se excluyó a los países socialistas. Se establecieron relacioneź con Bulgaria, Checoslovaquia y Polonia, y en octubre de 1966, con Rumania. A pesar de esto, la posición de Mobutu respecto de China era rígida. En diciembre de 1966 aceptó una invitación para visitar Formosa ${ }^{11}$. El mes anterior, sin embargo, había anunciado que restablecería las relaciones diplomáticas con la Unión Soviética.

A la luz de las actitudes subsiguientes de Bobutu, resulta claro que el reconocimiento internacional le fue concedido, no porque se tuviera mayor idea de lo que Mobutu estaba dispuesto a hacer, sino debido al alivio general por el hecho de haber sacado a Tshombe. En la práctica, en poco tiempo Mobutu se arrogó poderes más amplios que probablemente ningún otro jefe africano y la influencia del ejército cubrió áreas a las cuales anteriormente no se le había dado entrada. La lista de medidas tomadas por el nuevo régimen en sus primeras semanas y meses es muy ilustrativa. En diciembre de 1965, menos de un mes después del golpe, la jurisdicción de los tribunales mi-

\footnotetext{
10En una audición de la radio de Praga, el 15 de marzo de 1967, el locutor mencionó "los siguientes innegables factores: Mobutu fue amigo de Lunumba con anterioridad a la independencia, habiendo hecho esfuerzos por sacar a Lumumba de la prisión belga en la colonia, siendo posecdor de un carnet que lo acreditaba como micmbro del partido de Lumumba, con el número 201, aún cuando sc lo calíficaba de moderado en comparación con ia mentalidad avanzada de Patricio Litmumba". BBC Summary of World Broadcasts, 2a parte, Europa Oriental, 21 de marzo, 1967 (De açui en adelante será citado bajo SW'B.).

11El Ministro de Relaciones Exteriores de Mrobutu, Justin Bomboko, dijo en Conferencia de Prensa, en febrero de 1967 que, en 1966 "el Congo habia votado contra la entrada de China Popular a las Naciones Unidas debido a que cran contrarios a la política subversiva de esta última en Africa. Cuando China Popular cambic esta actitud, el Gobierno congoleño también podría revisar la suya". SIWB, t7 parte, El Mfedio Oriente y Africa, 23 febrero 1967.
} 
litares se extendió para incluir casos de corrupción, desfalco o despilfarro de bienes fiscales. Al mismo tiempo, la fuerza policial fue colocada bajo autoridad militar. En febrero de 1966, luego de una huelga de profesores, se suspendió el derecho a huelga a través de todo el país, por decreto presidencial. Esto último se enmendó posteriormente para hacerlo aparecer como menos drástico, pero sólo después que Mobutu prohibió la Confederación de Trabajadores Congoleses, arrestando a nueve de sus líderes, incluyendo al secretario general Malhonga, y dos de sus delegados. Según el Gobierno, éstos habían estado complotando contra Mobutu, y los informes de prensa indicaban que el slogan "obreros del mundo, unios" habia sido escrito en las paredes, al mismo tiempo que se habían encontrado fotografías de Mao y Castro-en las oficinas ${ }^{\mathbf{1 2}}$.

Inmediatamente después de su golpe de estado, Mobutu limitó los poderes del Parlamento sólo a la posibilidad de oponerse a los decretos que el Ejecutivo pudiera dictar, pero en marzo de 1966 eliminó incluso esto último, transfiriendo todos los poderes legislativos a la Presidencia. El Parlamento sería consultado acerca del presupuesto, pero no tendría derecho a debatir ninguna ley decretada por el Presidente, fuera pasada o futura.

Armado con esta impresionante pánoplia de poderes dictatoriales, la política de Mobutu comenzó a adquirir inconfundibles tonos nacionalistas, de los cuales el más notorio fue la decisión de que, a partir de julio de 1966, los nombres europeos de Ias ciudades congolesas deberían cambiarse. $\mathrm{Y}$ así, los nombres que había conocido el mundo en el breve intervalo entre 1960-1961, Leopoldville, Elisabethville, Stanleyville, Coquilhatville, deșaparecieron y pasaron a un virtual olvido, lo mismo que aquellos con que fueron reemplazados. ¿Quién que no sea un especialista puede recordar al instante cuál es Kinshasa, Lumumbashi, Kisangani o Mbandaka?

Mobutu, sin embargo, no se contentó con meros cambios simbólicos; la realidad congolesa también debería ser alterada. El rompimiento con el pasado significaba, en lo fundamental, un rompimiento con Tshombe. En consecuencia, Mobutu fue inevitablemente llevado a un conflicto con aquellos que creía respaldaban a Tshombe: el gobierno belga, el gobierno portugués y la Unión Mínera. Por otra parte, y tal como en años anteriores, el mayor problema lo constituía la reintegración de Katanga -donde todavía había importantes grupos que apoyaban a Tshombe- a la vida nacional congolesa.

22Le Monde, 11-12 diciembre 1966. 
Aun cuando Mobutu se colocó en el centro de la escena nacional con notable habilidad y rapidez, no logró dicho objetivo sin oposición interna. Es necesario admitir, sin embargo, que su desagradable método de aplastar a la oposición fue indiscutiblemente efectivo en asegurar que ésta no reaparecería bajo nuevas formas. La revuelta izquierdista, que pareció tan importante en 1964-65, terminó durante los primeros seis meses del régimen de Mobutu. M. Soumialot se habría retirado a Tanzania, seriamente herido por sus propios hombres, que no habían recibido su paga. Los señores Christophe Gbenye y Thomas Kanza estuvieron dirigiendo operaciones desde Kenia, para luego descubrir que, a radz del acercamiento entre Mobutu y Kenyatta, pasaron a ser personas no gratas en Kenia. Este parece haber sido también el destino de Nicolás Olenga, de quien se rumorea fue arrestado en Uganda. Antoine Gizenga, que inadecuadamente recibió el cetro de Lumumba, dejó el Congo en febrero de 1966, y reapareció luego en Moscú, donde anunció su intención de retornar al Congo "para defender los intereses del pueblo congolés".

Con sus líderes ausentes o desprestigiados, Mobutu pudo anunciar, el 5 de abril, que la rebelión había siḍo dominada. Sin embargo, ésta se mantuvo, aun cuando desvitalizada, hasta febrero de 1967, cuando informes de prensa revelaron que unidades del ANC, dirigidas por algunos 150 voluntarios blancos, thabłan iniciado una operación de limpieza en gran escala, cerca de Kisangani ${ }^{13}$. Pero Mobutu enfrentaba, además, otras amenazas, cerca de casa. El 30 de mayo de 1966, la radio de Leopoldville anunció que se habia descubierto un complot para derribar al Presidente Mobutu. Entre los arrestados se encontraba Evaristo Kimba, quien, siendo Primer Ministro en 1965, había sido derribado por Mobutu; Jerome Ananany y Alejandro Mahamba, ambos miembros del Gabinete presidido por Adoula, y Emanuel Bamba, antiguo asociado del ex presidente Kasavubu. Parece probable que ambos contaron con el apoyo de algunos sectores del ejército, pero que al último momento los oficiales dieron la espalda a los políticos, denunciándolos a Mobutu. La radio de Leopoldville informó que los complotadores intentaban hacer una proclamación señalando que -al asumir el control del Congo en noviembre de 1965- el Alto Comando del ANC nunca había tenido la intención de tomarse el poder por cinco años, como lo había hecho Mobutu. Continuaba diciendo que "durante ya seis meses, las instituciones legislativas se habian transformado en letra muerta y motivo de risa en el exterior", así como deploraban "la sistemática desorganización del aparato económico"14. Aun

2sSWB, 40 Parte, 6 febrero 1967.

${ }^{14 K e e s i n g s ~ C o n l e m p o r a r y ~ A r c h i v e s, ~ 18-25 ~ j u n i o ~ 1966, ~ p . ~} 21457$. 
cuando esto es menos probable, el Ministro de Informaciones de Mo. butu había alegado que los complotadores obraron en la presunción de que morirían alrededor de 10.000 soldados y civiles a consecuencia del golpe, en el que se intentaba asesinar a Mobutu y echar su cadáver al róo Congo.

El 31 de mayo tuvo lugar un rápido juicio delante de un tribunal militar, que consideró culpables a los cuatro acusados, sentenciándolos a muerte. El 2 de junio fue considerado feriado nacional, y la radio llamó a todos los ciudadanos de Leopoldville a ir a presenciar la ejecución. A pesar de las peticiones de clemencia de diplomáticos y otros, los cuatro desventurados políticos fueron públicámente colgados en la Gran Plaza.

Cuando se anunció por primera vez el descubrimiento del complot, se insinuó oscuramente que habría embajaclas extranjeras complicadas en el asunto. A raíz de esto, al principal personero político de la embajada belga se le dieron 24 horas para abandonar el país. Es dudoso que haya tenido algo que ver con los complotadores, sin embargo es sintomático de las relaciones entre Mobutu y Bélgica el que se haya elegido a un belga como la.víctima propiciatoria extranjera. En su campaña contra aquellos que consideraba como el respaldo de Tshombe, Mobutu había enfrentado el eslabón más débil de la cadena, el gobierno belga.

El 1.2 de mayo de 1966, anunció que su gobierno renegociaría los acuerdos firmados por Tshombe en Bruselas el 3 de febrero de 1955 (estos acueídos habían otorgado al Gobierno congolés el 17\% de participación en las actividades de la Unión Minera, tanto en el Congo como fuera de ese territorio. El Gobierno congolés también aceptó no alterar el sistema de derechos mineros vigentes, sin consulta y acuerdo previo). Según los congoleses, estos acuerdos ya no tenían validez, puesto que no habían sido ratificados por el Parlamento congoleño. Los asuntos no mejoraron con los comentarios que thizo Tshombe en París, ese mismo día. Sostuvo que todos los problemas de importancia entre el Congo y Bélgica habían sido ya arreglados por él. Dada In difícil situación del Congo, agregó, "necesitamos absolutamente de la cooperación del capital extranjero, y no es bueno asustarlo". Desde el punto de vista congolés, este tipo de observaciones parece destinado a estimular al capital extranjero a hacer aún otro intento para restituir a Tshombe en el poder. El Gabinete congolés rápidamente describió sus observaciones como "declaraciones demagrigicas que bordean la traición"; la Asamblea Nacional le quitó su banca y el Presidente 
Mobutu declaró el 24 de mayo que se iniciaría una investigación con vistas a acusar a Tshombe de traición ${ }^{15}$.

Hacia fines de mayo tuvieron lugar negociaciones entre el Congo y Bélgica, en Bruselas, habiéndose señalado que había acuerdo parcial, en un comunicado dado a publicidad el 27 de mayo. Los congoleses obtuvieron más que lo logrado por Tshombe, pero había que resolver algunas diferencias respecto a la línea aérea belga Sabena y otras compañías belgas que operaban en el Congo. Los congoleses, sin embargo, fracasaron en obtener la cancelación de la deuda que había sido negociada por Tshombe. El Congo tiene que pagar alrededor de 2.250.000 libras esterlinas anuales en francos belgas. Naturalmente que las disponibilidades de divisas - guardadas en la cuenta del Congo en el Banco Nacional de Bélgica- dependen de la continuidad de las ventas de cobre y otros minerales a través de la Unión Minera.

Las negociaciones con Bélgica fueron precedidas por manifestaciones populares antibelgas en el Congo, y aun cuando Mobutu prohibió una demostración importante que tendría lugar en Leopoldville, y ello en deferencia a la opinión belga, las relaciones entre ambos países se encontraban a un nivel extremadamente bajo. En consecuencia, cualquier historia por maliciosa que fuera, que colocara a los belgas a la sombra del neocolonialismo, tendía a sex creída por los congoleses. Cada vez que algo en este sentido ocurría, se culpaba inevitablemente a las maquinaciones de Bruselas y de Tshombe -al que Mobutu describe gráficamente como "un belga negro". El desarrollo de este burdo nacionalismo fue induclablemente impulsado por Mobutu y le fue de gran utilidad, tanto para tratar el perenne asunto de Katanga, como de refuerzo cuando se trató de dar la batalla final con la Unión Minera.

En todo caso, existió un temor genuino, y probablemente bien fundado, de que Tshombe, habiendo fallado como líder del Congo, complotara nuevamente para obtener la secesión de Katanga. Los antiguos gendarmes katangueses, actualmente enrolados en el ejército congolés y todavía con su equipo de mercenarios, presuntamente no ofrecían peligro en su lejana base de Kisangani (Stanleyville). Pero el 23 de julio de 1966 se tomaron el centro de la ciudad y el aeropuerto. Había alrededor de 3.000 gendarmes, los que con el tácito apoyo de algunos mercenarios blancos tuvieron pocas dificultades en arrasar con el elemento del ejército congolés que intentó oponérseles. Dos batallones de hombres recién entrenados no constituían peligro alguno para los experimentados katangueses. Mataron al jefe local, coronel José Tshatshi, soldado que había hecho su reputación destruyendo. la rebelión de Pierre Mulele, en Kwilu. Era curioso ver a estos katan-

${ }^{15}$ Tshombe fue juzgado in absentia en 1967, se le encontró culpable y sentenciado a muerte. 
gueses apoderándose de una ciudad durante tan largo tiempo asociada a los elementos revolucionarios más extremistas del Congo; en todo caso, los katangueses se demostraban felices con disponer nuevamente de una base de acción. Habían sido enviados mucho antes a esa área, en 1964, para ayudar a suprimir la rebelión, pero nunca habianse integrado completamente en el ANc.

Su rebelión, sin embargo, no fue totalmente exitasa, incluso si sólo se considera el limitado objetivo que representó la toma de Kisangani. Mientras que los rebeldes, dirigidos poì el coronel Tshipula (su vocero, si no su líder) tenian a su servicio unos treinta mercenarios, un número mayor, alrededor de 70 , controlados por el-soldado francés teniente coronel Robert Denard, permanecieron fieles a las fuerzas leales del ANC, logrando este último grupo mantener el control de la estación de radio y el edificio de correos. Dada la situación, lo probable fue que la estación de radio probara ser más útil a Denard que el aeropuerto a Tshipula. Denard estuvo en condiciones de informar a Mobutu, en Kinshasa, exactamente de todo lo ocurrido.

No cabe duda que éste fue un momento difícil para Mobutu. En efecto, en esos instantes se encontraba enteramente en manos de los katangueses. No tenía tropas disponibles para enviar a aplastar la revuelta. Los rebeldes comenzaban a sentirse en su casa en Kisangani, e incluso ofrecieron tomarse la región para Tshombe, si éste expresaba interés en regresar. No había nada que hacer, sino parlamentar. Mobutu comisionó al Primer Ministro Mulamba para que efectuara esta misión, y al mismo tiempo ordenó se investigara el problema de la paga a los gendarmes (Mobutu era experto en aquellos factores que provocan descontento entre los militares).

Mulamba no demostró ser un negociador de éxito, y. la lucha se restableció abiertamente (Mulamba habría de pagar su fracaso posteriormente. El 26 de octubre dejó de ser Primer Ministro y luego fue nombrado presidente del Consejo de la recién nacionalizada empresa estatal de seguros sonas. Se tiene entendido que su dimisión fue causada por la presión de sectores del ANC que estimaron su actitud frente al motín de Kisangani como no lo suficientemente firme). Su fracaso fue seguido por el curioso espectáculo del Sr. Munongo, Gobernador de Katanga del Sur, ardiente admirador, durante mucho tiempo, de Tshombe, y a opinión de algunos, el asesino de Lumumba, en calidad de enviado especial a Kisangani en misión de reconciliación. Munongo no tuvo más éxito que Mulamba, y aun cuando este último anunció a su vuelta a Kinshasa, el 5 de agosto, que se habla llegado a un acuerdo de cese de fuego, se vio obligado a agregar que el asunto no estaba aún definitivamente arreglado. De hecho no habia 
síntomas de que pudiera estarlo. Los amotinados pedian ser pagados y que se les diera nuevo equipo. Esto podía concedérseles con mucha dificultad. Pero, además pedían ser devueltos a Katanga, lo que Mobutu ni siquiera podía considerar. Los acontecimientos en esa provincia eran ya ló suficientemente difíciles de controlar como para agravarlos con el retorno de la gendarmería.

El problema que representaban los rebeldes no se resolvió ni siquiera al aplastarse completamente la rebelión, ni tampoco con la captura del coronel Tshipula. Los periodistas belgas insinuaron que Tshipula y sus compañeros habían sido quemados vivos, probablemente sobre la base de que, luego de la ejecución pública del Primer Ministro Kimba, sus lectores aceptarian cualquier historia de terror acerca del Congo. Esto fue excusa suficiente para que Mobutu prohibiera en el Congo la circulación de los periódicos derechistas La Libre Belgique y Pourquoi pas? En todo caso, para refutar el reportaje había que presentar a los prisioneros.

Fueron sometidos a juicio a comienzos de diciembre. Sin embargo, considerando probablemente que su muerte podria significar mayor intranquilidad entre los katangueses, el juicio fue postergado por razones de procedimiento y, luego, simplemente abandonado.

La importancia interna del motín de Kisangani estuvo en que agregó validez a la continua afluencia de historias de radio Kinshasa acerca de complots planeados por Tshombe y los imperialistas. No fue sino hasta el 25 de septiembre - dos meses después del estallido del motín- que las fuerzas leales pudieron recuperar el control de Stanleyville. Durante este tiempo se dieron a conocer dos versiones razonablemente posibles sobre presuntas maquinaciones imperialistas.

La primera apareció casi inmediatamente después que se diera a conocer la existencia de la rebelión. Esta última, según anunció la prensa congolesa, fue parte de un complot para reponer a Tshombe en el poder. Dos de los principales colaboradores de Tshombe, se decia, habían visitado Rodesia y Sudáfrica con el objeto de convencer a dos conocidos líderes mercenarios, los tenientes coronel Hoare y mayor Wicks, para que reclutaran unos 150 mercenarios. Estas tropas constituirian la avanzada del grupo que promovería la revuelta general, conducente a derribar a Mobutu y reemplazarlo por Tshombe. El plan tuvo que ser abandonado debido a la no participación de Mike Hoare y a que su sucesor, el mayor Peters, informó al general Mobutu acerca del mismo. Sin embargo, esto no ocurrió con la rapidez suficiente para impedir que la gendarmería de Kisangani cumpliera con su parte del plan. 
Sea o no cierta la historia, y tiene a su alrededor un aura de verdad, fue útil para Mobutu, en cuanto a medio de crear una atmósfera de permanente amenaza, tanto interna como externa, muy importante para la consolidación de su régimen. Sin embargo, la segunda interpretación, cuyos detalles empezaron a ser conocidos a fines de septiembre, tenía un respaldo más sólido. El 17 de septiembre, la policía francesa arrestó a alrededor de treinta hombres en un campo en las Ardennes. Entre éstos había un belga, M. Thierry de Bonnay, quien se presumia reclutaba mercenarios para el Congo: Más aún, entre los arrestados estaba el editor parisiense del semanario tunecino Jeune Afrique, Sr. Mohammed Bahri, y el Sr. Aniceto Kashamura, quien años anteriores lrabía sido niembro del gabinete de Lumumba. Aparentemente, los mercenarios reunidos en la granja habian solicitado a Kashamura que viera modo de darles publicidad, la que a su vez les significara fondos (tal como ocure con todos los soldados mencionados en esta historia, no liabian recibido paga en semanas). Obtuvieron publicidad - Jeune Afrique salió a la circulación con la historia (Bahri y Kashamura fueron rápidamente puestos en libertad por la policía francesa) - pero no exactamente el tipo de publicidad que deseaban. El 22 de septiembre, 12 personas fueron arrestadas en la granja, incluyendo a Bonnay y a un ex coronel de la Fuerza Aérea norteamericana, George Holmquist, quienes fueron enviados a París, para ser sometidos a juicio por reclutar soldados en territorio francés y por cuenta de un gobierno extranjero. De acuerdo con la historia publicada por Jeune Afrique, Tshombe habia dispuesto que alrededor de cinco millones de francos fueran puestos a disposición de M[r. Bonnay con el objeto de reclutar mercenarios. Se habia preparado una flotilla de aviones para la ocupación de Katanga y Kasai. Guando llegara el momento de la acción, el propio Tshombe tomaría la dirección de la operación desde una base segura en Angola, país que además podría proveer refuerzos mercenarios.

Las declaraciones de Tshombe acerca de la existencia del campo y del plan no eran como para inspirar confianza en su veracidad. En primera instancia, anunció que no lo conocía. Sugirió que las acusaciones contituian una "puesta en escena" de Mobutu para desviar la atención sobre los verdaderos problemas del Congo. En seguida reveló que sabía de la existencia del campo y que él mismo había informado a la policía francesa. Agregó luego que se le había ofrecido el uso de los mercenarios, pero que no había querido hacerse cargo de la of́erta.

Con rapidez se reactivó el enojo congolés en su contra. Se anunció que sería procesado in absentia por una Corte Mrilitar, acusado de alta traición. Se envió una nota de protesta al gobierno español, recla- 
mando por el hecho de residir Tshombe en ese pais; en octubre, varios miembros del Parlamento congolés solicitaron la ruptura de relaciones con España, en vista de la política de este pafs de conceder asilo a Tshombe.

Sin embargo, el enojo contra España no era nada comparado con el resentimiento frente a Portugal. La radio de Kinshasa anunció el 19 de septiembre que un numeroso grupo de mercenarios reclutados por Tshombe se había reunido en Angola, cerca del límite con Katanga. Aun cuando el Ministro de Relaciones Exteriores de Portugal rápidamente negó la versión, el Gobierno del Congo reclamó ante el Consejo de Seguridad porque Portugal "usaba su territorio africano como base de operaciones para mercenarios reclutados en Europa y llevados via Lisboa a Angola y Cabinda". Estos mercenarios, seguía la reclamación, estaban "al servicio de Mr. Tshombe" y habían sido reunidos "con el objeto de derramar sangre congoleña para decribar a las legítimas y legales autoriclades del país".

La campaña anti-Portugal del Gobierno se vio rápidamente acompañada de agitación popular. El 24 de septiembre, la embajada portuguesa en Kinshasa fue saqueada por una multitud iracunda y, al día siguiente, una gran masa efectuó demostraciones en pro de una ruptura de relaciones con Portugal. Los demostradores se vieron fuertemente reforzados por refugiados de Angola, quienes tentan sus propias razones para ser antiportugueses. Había una razón adicional para reclamar, y era que el cuartel general en Kinshasa del gobierno revolucionario en exilio de Angola, de Holden Roberto, había sido también saqueado, por instigación de un diplomático portugués. Dichas manifestaciones, a niveles gubernamentales y populares, terminaron inevitablemente en una ruptura con Portugal. Dado que Portugal es el principal enemigo europeo en Africa, la anterior fue una buena carta jugada por Mobutu, tanto en términos de asegurar unidad en el frente interno como en reforzar sus credenciales anticolonialistas a los ojos del resto de los Estados africanos.

El rompimiento con Portugal tuvo lugar en periodo de máxima incertidumbre en los asuntos del Congo, los que llegaron a su nivel de tensión más alta en diciembre de 1966, en que se rompieron las cruciales negociaciones entre el Gobierno del Congo y la Unión Minera. El mes de diciembre se caracterizó además por la renovación de la amenaza de una eventual vuelta de Tshombe y seria intranquilidad en Katanga. 
La medida de los problemas se infiere de la proliferación de rumores acerca de la inminente caida de Mobutu. Fue indiscutiblemente muy notorio el que Mobutu suspendiera los viajes al exterior. En diciembre postergó de hecho una visita de estado a Tanzania, relacionada con el tercer aniversario de la Unión de Tanganyika y Zanzíbar, ocasión esta última en que envió al Presidente del Senado, Sr. Mundingay, y a Víctor Nendaka, Ministro de Transportes. Tampoco aceptó invitaciones para asistir a las celebraciones de aniversario en Zambia y la República Centroafricana, como tampoco estuvo presente en las reuniones de jefes de Estado, consocada por la Organización de Estados Africanos en Addis Abeba, en noviembre.

Luego, fueron inevitables los rumores acerca de aquellos que, de acuerdo al pintoresco lenguaje de la radio de Kinshasa, "aprovecharian la ventaja de una ausencia del Jefe de Estado, para eliminarlo del poder a beneficio de quienes ustedes conocen, principalmente Moise Tshombe, titere de la alta finanza internacional"16.

Es muy difícil precisar si los rumores eran serios, o si Mobutu tomó simplemente elementales precauciones, o si sólo se trató de falta de tiempo para excursiones internacionales. En todo caso, no cabe duda que el golpe de estado de Ghana, ocurrido durante" el viaje de Nkrumah a Pekín, ha dado mucho que pensar a los africanos.

Incluso se sugirió en ese tiempo que la Comunidad Británica de Naciones no sería ya una institución viable, puesto que los Primeros Ministros de las naciones que la integrain no se sentían en posición de abandonar el pais por temor a una revuelta en su ausencia.

Mobutu, por su parte, tue muy duro en su crítica al coronel Micombero, que organizó un golpe en Burundi el 28 de noviembre de 1966. Para deponer al Rey Nteto $v$, mientras este último estaba de visita en Kinshasa. A raiz de este último levantamiento, en los clías inmediatamente anteriores a su enfrentamiento con la Unión Minera y de la intranquilidad en Katanga, Mobutu canceló su viaje a Dar es Salaam. Pero, tal como lo explicara el mismo Mobutu a la agencia de prensa congolesa en diciembre, no era necesario que un jefe de Estado estuviera ausente para que se gestara un golpe. En noviem- . bre de 1965, él no había esperado que Tshombe y Kasavubu abandonaran el país". "En la actualidad", declaró, "no veo a nadie que levante cabeza y desafie mis decisiones, las que se toman de acuerdo a los intereses de la nación congolesa. Un régimen diferente al mío estaria cavando su propia tumba, pues hemos llegado al punto límite, en que ya es imposible retroceder". En todo caso, las drásticas medidas

${ }^{10}$ SWB, 4 Parte, 10 diciembre 1966, informando de una transmisión del 8 de diciembre. 17Ibid. 
tomadas en contra de Evariste Kimba y los anteriores ministros de Tshombe, fueron probablemente un efectivo disuasivo. Sin embargo, Radio Kinshasa anunció el 15 de diciembre, al comentar las especulaciones en torno a las cancelaciones de los viajes al extranjero de Mobutu, que "ahora podemos afirmar que esto ocurrió por consejo de muchos Presidentes de Estados Africanos, quienes sugirieron que no abandonara su pais"18.

Cualesquiera que hayan sido los motivos que provocaron la reticencia de Mobutu ante los viajes al extranjero, no cabe duda que tuvo razón al no viajar. El esquema del desarrollo de los acontecimientos en Katanga en diciembre de 1966 no es claro, pero los rumores circulantes eran suficientes para crear una atmósfera de crisis, más urgente aún debido a los movimientos de tropas en la misma provincia de Katanga y en Angola, y al general levantamiento administrativo. El panorama, tal como se veía en Kinshasa, puede visualizarse del informe de Radio Kinshasa, el 9 de diciembre:

"Se ha informado por fuentes cercanas al servicio de seguridad nacional, que el gobierno de Smith estaría actualmente estudiando la posibilidad de participar con voluntarios rodésicos en la llamada "Operación Elefante", organizada por Moise Tshombe con vista a una intervención militar en Katanga. Se informa asimismo, que Rodesia le habria indicado a $M$. Tshombe que su fuerza militar podría terminar su entrenamiento en territorio rodésico. Al parecer, el servicio de inteligencia congolés recibió información precisa en relación a la preparación para una intervención militar en Katanga, con el objeto de dejar a Tshombe con el control de esa provincia mediante la ayuda de Rodesia"19.

La fuente de esta información fue, presuntivamente, una carta fechada el 5 de noviembre, dirigida a Tshombe en Madrid por un representante del Ministerio de Información de Rodesia. No es posible asegurar que todo el asunto no fuera prefabricado, pero no cabe duda que habrfa sido interesante para Rodesia el tener instalado en Katanga a un Tshombe benevolente, con mano firme sobre el ferrocarril que permite la salida al mar a Zambia. Tal como lo señaló un comentarista de la radio de Salisbury, poco después que Portugal amenazó con cerrar el ferrocarril de Ndola a Benguela y Lobito:

"Desde la independencia de Rodesia, el Presidente Kaunda ha llegado a extremos con tal de evitar el envio de cobre a través 
de Rodesia. Abiertamente ha destacado el uso del camino que lo une a Tanzania, para dar salida a los productos de Zambia. Pero, a pesar de esto, la mayor parte del cobre de Zambia ha salido por Ndola. Ahora que esta ruta se encuentra en peligro, y debido a que la ruta por Tanzania está prácticamente cerrada por las lluvias, el Presidente Kaunda deberá pensar dos veces su actitud hacia Rodesia, si es que desea salvar la tambaleante economía de Zambia, e incluso su propia posición como jefe de Estado' 20

Acerca de que Rodesia habría encontrado más cooperación en una Katanga controlada por Tshombe, no cabe duda; ello se desprende de una conferencia de prensa dada por el Ministro de Relaciones Exteriores de Mobutu, M. Justin Bomboko, el 22 de diciembre, en la que señaló que aquéllos (Rodesia) nada ganarían con Mobutu. De acuerdo a un informe de radio Kinshasa:

“M. Bomboko deploró la pasiviclad del Gobierno británico, el cual, a pesar de las advertencias del Gobierno congolés, continuó en una actitud que no resolvía la crisis de Rodesia. Luego agregó enfáticamente que la única manera de dejar fuera de acción a esa banda de racistas en el mínimo de tiempo posible, era mediante el uso de medidas coercitivas. Esto era imperativo"21.

Respecto a las sanciones,

"M. Bomboko dijo que muy luego propondría al gobierno algunas medidas prácticas, especialmente la obligación de suspender las importaciones desde Rodesia de ciertos productos, especialmente carbón, a algunas compañías, las cuales, señaló, fueron advertidas diez meses atrás que deberían encontrar una fuente alternativa de abastecimiento. El Congo no desea, dijo, ser acusado de colaboración con el régimen de Smith".

Ante declaraciones de esa naturaleza, los rodésicos podian esperar poca cooperación de Mobutu. De hecho; el Presidente congolés aclaró aún más su posición en un discurso en la décima sesión del Comité de Liberación de la ouA (Organización Unidad Africana), reunida en Kinshasa el 30 de enero de 1967, cuando declaró que "la República Democrática del Congo siempre estará al lado de la ouA, en el caso que ésta decidiera una acción militar contra la rebelde Rodesia"22.

ns NW $^{\prime} B$, 40 Parte, 31 diciembre 1966. " $S W H B$, 44 Parte, 30 diciembre 1966. 2si'B, 4. Parte, 2 febrero 1967. 
Sin embargo, Rodesia difícilmente podía admitir que complotaba para derrocar a Mobutu, y naturalmente que la historia de la "Operación Elefante" fue enfáticamente negada en Salisbury.

Haya sido verdadera o no aquella historia, el Gobierno de Kinshasa no corrió ningún albur ante lo que podría ocurrir en diciembre en Katanga. Frente al rumor de que ochenta mercenarios hablan viajado vía aérea desde Bélgica a Angola, se transfirieron al sur tropas de la ANG que habían estado comprometidas en acción contra remanentes rebeldes en otras partes del Congo. La radio de Bukavu, el 19 de diciembre, informó que fuerzas de seguridad patrullaban la totalidad de Lumumbashi (Elisabethville) "con el objeto de mantener la paz". En los dias anteriores, informes de prensa establecian que numerosos bloqueos de caminos habían sido instalados en las carreteras claves de Katanga, yr que el aeropuerto de Lumumbashi estaba bajo fuerte guar$\mathrm{dia}^{23}$. De acuerdo con lo indicado por la agencia de prensa congolesa, "los enemigos de la república" planeaban un asalto desde Angola y Rodesia contra esa 'parte del país.

Hubo un estallido importante, pero no tuvo lugar ni en Katanga, ni en la frontera con Angola. El día de Navidad se produjo un importante choque entre tropas portuguesas y rebeldes angoleños en Texeira de Sousa, cerca del límite con Katanga, sobre la vía férrea clave para el transporte del cobre. Según se informó, los zambeses estaban también comprometidos, y Zambia movilizó tropas a su frontera con Angola. Durante breves momentos la vía férrea en cuestión estuvo interrumpida, y se esparcieron rumores en el sentido de que Portugal, en represalia por lo ocurrido, planeaba prohibir todo embarque de cobre zambés por puertos portugueses.

En definitiva, sólo se trató de una tormenta en un vaso de agua, aun cuando obviamente, los congoleses seguían preocupados por la seguridad de Katanga. En un importante discurso, el 24 de diciembre, Mobutu dio a conocer una serie de reformas administrativas que afec. tarían á Katanga y que entrarłan en vigencia inmediatamente.

Básicamente, la reforma consistía en una reducción en el número de provincias del Congo. En abril de 1966, éstas fueron reducidas de 21 a 1.2, y ahora fueron disminuidas a 8 . Esto era lo único posible para terminar con "las interminables habladurfas de ambiciosos polfticos", dijo el subgobernador de Kasai Occidental. Las medidas tomadas fueron estrictas: todos los gobernadores provinciales serían, de ahora en adelante, servidores civiles, y no podrfan trabajar en su región de origen. Esto, según explicó Mobutu, era una medida contra el tribalismo. "No queremos menospreciar las peculiaridades nacio-

W.e Monde, 16 diciembre 1966. 
nales; sólo queremos defendernos de las características negativas, vale decir, aquellas que no están destinadas a crear un Estado congolés unido". Al apretar el control sobre las provincias, Mobutu aprovechaba la oportunidad de reducir su Gabinete. Ocho ministros fueron despedidos, y el total reducido de 21 a 17.

En Katanga mismo, la reforma significó una serie de rápidas elecciones. Primero, había que sacar del camino a M. Munongo, el gobernador de Katanga del Sur. Ya habla sido suspendido de su cargo, unos meses antes de la rebelión de Kisangani; habiendo sido reemplazado por un soldado, el general Leopold Massiala. El 25 de diciembre, un decreto presidencial los eliminó formalmente, tanto a aquél como a los gobernadores de Katanga del Norte y del Alto Congo. Un segundo decreto, del mismo día, llamó a las asambleas provinciales de esas tres provincias para elegir nuevos gobernadores, el 26 de diciembre. Cualquier ciudadano normalmente elegible podía presentarse a la elección, con la excepción de los tres despojados de su cargo. Los partidarios de Munongo trataron de elegirlo, pero, dada la prohibición, presentaron como candidato a Paul Muhona, el anterior ministro de salud de Katanga del Sur. Logró entrar por un voto. Al día siguiente, 27 de diciembre, tuvieron lugar elecciones en las asambleas provinciales de todo el país, con el objeto de elegir nuevos gobernadores para las nuevas provincias reunificadas. Sólo los gobernadores existentes podian presentarse a elección. De esta manera, en la provincia de Katanga, resultante de la fusión entre Katanga del Sur y del Norte, Paul Muhona ganó por segunda vez en dos días. Sin embargo, si los partidarios de Munongo alcanzaron a celebrar el triunfo, lo hicieron prematuramente, puesto que ningún gobernador podía ejercer su cargo en su región de origen, por lo tanto Muhona se encontró transferido como gobernador de Kasai Occidental, el 2 de enero de 1967.

Una nueva medida para reforzar el control del gobierno central sobre Katanga fue la decisión de que todos los consulados extranjeros en el Congo sólo podrían comunicarse con sus respectivos países, de esa fecha en adelante, a través de sus embajadas en Kinshasa. Había alrededor de 40 de esos consulados, y desde luego que los más importantes se encontraban en Lumumbashi. Aun cuando en noviembre habían recibido orden de cerrar, ésta había sido suspendida. Una vez cumplida, ésta probó ser una medida importante para impedir las interferencias extranjeras a un nivel regional. Al mismo tiempo, se prohibió a las oficinas de la Unión Minera en Katanga toda comunicación directa con Bruselas; esto último, sin embargo, formaba parte de una estrategia diferente: el enfrentamiento con la Unión Minera. 


\begin{abstract}
"Dentro de la historia de la decolonización econo. mica de Africa, la 'congolización' de la Unión Minera de Alto Katanga 'es, indiscutiblemente, el paso más importante desde la nacionnlización del canal de Suez".

M. JOSEPH Mreke, Embajador del Congo en París, 28 diciembre, 1966.
\end{abstract}

La Unión Minera, con oficinas principales en Bruselas, hasta fines de 1966, era la tercera compañía productora de cobre del mundo, tercera clespués de las enormes empresas norteamericanas Kennecott y Anaconda. Además de cobre, sus minas congolesas producen el $60 \%$ del consumo occidental de cobalto, para no mencionar el cadmio, metales preciosos, uranio y casi la totalidad del abastecimiento mundial de rádium. La compañía empleaba en el Congo a 22.366 africanos, lo que significa, incluyendo a sus familias, là responsabilidad por el bienestar de 107.000 personas, de los cuales un $18.5 \%$ recibía casas de la compañia, quien también organizaba a través de su sistema de distribución la alimentación de los mismos. Indispensable para las operaciones mineras eran 1.500 técnicos belgas, quienes recibían la mitad de su salario en francos belgas y en Bélgica.

El gobierno congolés, para los efectos de financiar sus propias actividades, dependía casi totalmente de las operaciones de la Unión Minera. Los impuestos a las exportaciones de cobre proveían casi la mitad de los recursos del Tesoro congolés y el $70 \%$ cle las entradas en divisas extranjeras. En editorial del 27 de cliciembre de 1966, Le Monde explicaba que una paralización en la producción tendría los mismos efectos que la secesión de Katanga sobre los planes económicos del gobierno central. El Presidente Mobutu no hacía una referencia meramente retórica al decir en un discurso ante el Parlamento congolés, el 24 de diciembre de 1966, "si para ser libres e independientes deberemos ayunar, pues ayunaremos durante meses si es necesario". Si se interrumpía la continuidad en las entradas del cobre, el Congo no tenía otra alternativa que el ayuno.

La Unión Minera, bajo la presidencia del anciano M. Louis Wallef, rara vez hizo alguna concesión significativa al nacionalismo congolés, y es necesario agregar que la compañía nunca llegó a ponerse de acuerdo con la idea de la independencia del Congo. Fue ampliamente culpada por la secesión de Katanga, dirigida por $M$. Tshombe en 1960, y no cabía duda que cualquier régimen genuinamente nacionalista que llegara al poder en Leopoldville, tarde o temprano se vería. 
forzado a un rompimiento abierto con la compañía. Los primeros movimientos de Mobutu fueron tentatiros, pero en la medida que gradualmente fue asegurando su control sobre la totalidad del pais, se sintió crecientemente más capaz de tomar una línea dura. Aclemás, se dieron algunos síntomas ocasionales de que la Unión Minera ya no contaría con un respaldo tan fuerte del gobierno belga como el que demostró tener durante los clías de la secesión de Katanga. En esas circunstancias, Mobutu tenía al menos cierta posibilidad de éxito en cualquier batalla que quisiera provocar con la Unión Minera.

Los primeros rounds de la pelea se dieron en mayo de 196'6, cuando la Unión Minera duplicó el precio de su cobre, para colocarlo al mismo nivel de las recientes alzas de Chile y Zambia. Mobutu rápidamente acusó a la compañía de actuar "como un estado dentro del estado", sosteniendo que la decisión de la Unión Minera se había tomado sin ninguna consulta con el Gobierno del Congo. En represalia, el Gabinete decidió subir el impuesto a la exportación de cobre en un $30 \% \mathrm{y}$, con vistas a mantener un control más cercano sobre las actividades de la Unión Minera, se insistió en que las empresas que operaban en el Congo trasladasen sus oficinas principales a este territorio antes de fines de año.

En un principio pareció que la compañía belga aceptaría cumplir con ese pedido. $M$. Wallef anunció el 26 de mayo que se construiría a corto plazo un gran edificio en Kinshasa, con el objeto de acomodar las oficinas administrativas de la compañia. Pero esto no representó más que un gesto de conciliación hacia los congoleses, cuya principal preocupación era, desde Iuego, el que las oficinas principales de la empresa se trasladaran de hecho al Congo. Esta medida, como certeramente lo anotó M. Wallef, "entrañaba graves dificultades, clebido principalmente a las implicaciones fiscales, tanto en el Congo como en Bélgica”. Forzar a la Unión Minera a transferir sus oficinas principales a Kinshasa era desafiar a un enfrentamiento frontal, cosa que Mobutu en un principio pareció ansioso de evitar. Y había más en camino. El 7\% de junio, Mobutu firmó la llamada Ley Bakajika, mediante la cual el Congo recuperaba el dominio total de los derechos concedidos, o cedidos, antes de la independencia, sobre la tierra, forestaciones o yacimientos mineros, sea que éstos hubieran sido concedidos en propiedad o en participación con terceras partes, de hecho o en derecho.

Mediante la aprobación de esta Ley, Mobutu teóricamente colocaba a la Unión Minera en difícil posición. O la compañía se trasladaba a Kinshasa, doncle se vería obligada a aceptar mayores tasas tributarias, o se quedaba en Bruselas, para descubrir que el lucrativo sub-

$$
\left[\begin{array}{lll}
4 & 6 & 6
\end{array}\right]
$$


suelo congolés había sido reivinclicado por sus dueños. Sin embargo, a pesar que Mobutu podía hacer lo que quisiera con la ley, la Unión Minera aún era clueña del dinero. Puesto que ninguna de las partes, al menos al comienzo, se veía dispuesta a jugar su carta de triunfo, las negociaciones prosiguieron durante todo 1966, y parecía que se encontraban a punto de acuerdo a fines de noviembre. Un comentario de radio Kinshasa explicaba la nueva situación el 30 de noviembre, dando testimonio del optimismo del gobierno:

"el principal objetivo del nuevo régimen... es recuperar la independencia económica del país... estamos a punto de ganar la batalla... Las negociaciones que nuestros expertos han llevado con altos personeros de la Unión Minera de Katanga han producido, de hecho, los siguientes resultados: La Unión Minera como tal, suspenderá sus actividades en el Congo a partir de la medianoche del 31 de diciembre. Será reemplazada, a partir de las 00.01 del 19 de enero de 1967, por la Unión Minera del Congo, compañía en la cual el Gobierno será dueño de la mitad de las acciones... A este ritmo, y si nadie coloca trampas en nuestro camino, tenemos buenos motivos para esperar que, para 1970, la totalidad de la economía del país se encontrará en manos de este país" ${ }^{24}$.

La verdad es que se había llegado a acuerdo entre el gobierno y la compañła sobre los siguientes puntos:

a) La Unión Minera del Alto Katanga cambiaría su nombre por el de Unión Minera y Metalúrgica. Este sería aplicable a la totalidad de la empresa, y no sólo a la parte de ésta que tenía intereses en el Congo;

b) Todo el activo de la compañía en el Congo sería traspasado a una nueva empresa, llamada Unión Minera del Conigo, con oficinas principales en Kinshasa;

c) El Gobierno congolés sería propietario del $50 \%$ de las acciones de esta nueva compañía (contra 24 y $25 \%$ de la antigua Unión Minera del Alto Katanga) ; el remanente $50 \%$ quedarfa en poder de la Unión Minera y Metalúngica, y

d) El Gobierno congolés retendría su participación del 17\% del total del activo fijo y liquidable de la nueva Unión Minera y Metalúrgica en todas partes del mundo, as como su $25 \%$ en derecho a voto en el Directorio 25.

No cabe duda que los directores de la Unión Minera habian hecho importantes concesiones, aun cuando resulta igualmente claro que

=Kecsings Contemporary Archives, 7-14 enero 1967, p. 21807. 
éstas eran insuficientes para aquellos que no estaban dispuestos a tolerar nada que no fuera la nacionalización directa. De hecho, el acuerdo apenas había sido aprobado en principio, cuando ya había fracasado. El punto de choque estuvo aparentemente en la demanda de la Unión Minera en el sentido de mantener el control sobre el comercio del cobre, frente al sentimiento congoles de que no tenían suficiente voz en lo relativo a la aceleración del "pipeline" (el tiempo que transcurre entre la producción minera en el Congo y el procesamiento y venta en Bélgica). Se piensa además en una seria diferencia de opinión entre los 65 años de M. Wallef y la relativa juventud del Presidente Mobutu²6.

Al fracasar el acuerdo, la situación volvió a ser la prevaleciente antes del comienzo de las dișcusiones. El Presidente Mobutu volvió a su posición previa en los puntos más sutiles en el plano legal: "espero que el Gobierno belga use su influencia sobre la Unión Minera para hacerla comprender que en el Congo no hay solamente cobre, sino también leyes". Reiteró, además, el ultimátum de mayo. La Unión Minera debía trásladar sus oficinas principales al Congo: "He explicado al Embajador belga que terminaron todas las negociaciones para la creación de dos compañías. La Unión Minera del Alto Katanga continúa, y debe instalarse en Kinshasa, como cualquier otra empresa congolesa". Esta parecía una posición de por sí ya bastante firme, pero el Presidente le agregó una explicación. "Esto no significa aún que nosotros estemos considerando la nacionalización, pero aplicaremos la Ley Bakajika, mediante la cual el Congo pasa a ser el dueño de su suelo".

Mobutu clarificó lo anterior en una entrevista publicada a la semana siguiente, el 18 de diciembre, en el periódico belga Le Soir, en la cual además dejó traslucir su molestia frente a los ancianos directores de la Unión Minera. El primero del mes siguiente, dijo:

"la Unión Minera no dispondrá de un solo metro que explotar aquif en el Congo. S.i todo marcha bien, estamos preparados para esperar otros cuatro, cinco, e incluso seis años, si esto es necesario; transcurrido este tiempo, los actuales directores de la Unión Minera habrán sido removidos o habrán caducado sus contratos. El Gobierno del Congo iniciará entonces negociaciones con directores más jóvenes, con los cuales será posible llegar a un acuerdo"27.

Al ser preguntado qué sucedería si las cosas no fueran bien, "el

20"What went wrong at Union Minicre?", Times, 11 cnero 1967. 2:SW'B, 44 Parte, 21 diciembre 1966. 
general Mobutu replicó que había otro camino. Se solicitaría a otra nación que viniera a explotar las minas en el Congo". Con esta enigmática anotación, el Presidente terminó la entrevista.

Frente a estas amenazas, los directores de la Unión Minera rear.cionaron con característica calma. El 22 de diciembre anunciaron:

"el domicilio y dirección administrativa de la compañía no serán transferidos a Kinshasa. Este cambio implica, por un lado, el consentimiento unánime de los accionistas, y por otro lado, significaría colocar bajo la jurisdicción congolesa todo el activo de la empresa fuera del Congo, privando asi a accionistas, empleados y terceros de la seguridad que ellos estiman indispensable".

Apenas había dado. a conocer la anterior declaración, el Gobierno congolés suspendió todos los embarques de cobre desde el Congo, cl 23 de diciembre. Al mismo tiempo, anunció la formación cle una nueva empresa para reemplazar a la Unión Minera. Debido a la rapidez con que esto se efectuó, Le Monde informó que algunos observadores parecian creer que "tal vez se habria llegado a un acuerdo en principio entre el Gobierno congolés y algunos grupos privados (quizás ya representados en la Unión Minera) antes de la decisión del consejo administrativo de la empresa de no mover sus oficinas principales a Kinshasa"'28.

Es probable que los congoleses se hayan visto estimulados por la existencia de un frente dividido en el Consejo de la Unión Minera, pero en todo caso, parecen haber definitivamente tenido la esperanza de una división entre la compañía y el Gobierno belga. El Ministro de Relaciones Exteriores del Congo, M. Bomboko, estaba en Bruselas durante la tercera semana de diciembre, ostensiblemente para reclamar al gobierno de M. Van den Boeynant por el reclutamiento de mercenarios en Bélgica, para ayudar a M. Tshombe. Al ser interrogado, en el aeropuerto de Kinshasa, a su arribo el 22 de diciembre, declaró que durante su estada en Bruselas "había sido sorprendido y reconfortado por el hecho de que Unión Minera, contrariamente a lo esperado, no contaba con el apoyo del Gobierno belga, y que tampoco gozaba del apoyo de ciertos sectores de la ciudadanía en general, lo que comprueba la verdad de la posición congolesa" 20 .

Es difícil precisar si dichas consideraciones realmente pesaron sobre Mobutu y sus asesores. Parece más probable que se vieran empujados por el propio curso de los acontecimientos, y que cada nuevo paso para obtener el control del cobre había sido pensado sólo en términos

Le Monde, 25-26 diciembre 1966.

20SWB, 4* Parte, 30 diciembre 1966. 
de slogan. Nada hace pensar que alguien haya pensado en qué sucedería si la Unión Minera decidiera reducir sus pérdidas en el Congo. No hay duda que Mobutu estaba preocupado con las posibles represalias de la Unión Minera. Por ejemplo, la compañía podría bloquear la participación del Gobierno congolés en las actividades de la Unión Minera fuera del Congo. En consonancia con los acuerdos SpaakTshombe, de febrero de 1965, el Gobierno congolés controlaba el $17 \%$ del total de la actividad mundial de la Unión Minera, lo que fue concedido a cambio del compromiso de que el Gobierno no cambiaría unilateralmente los acuerdos vigentes con la empresa. Pero esta posible ventaja de la compañia aparecía neutralizada por el hecho, puntualizado por el mismo Mobutu en un importante discurso ante el Parlamento, el 24 de diciembre, de que la empresa matriz de la Unión Minera - la Societé Générale de Belgique- tenía grandes intereses en el Congo, los que pagarían los pecados de la Unión Minera ${ }^{30}$.

La nueva empresa propuesta por los congoleses para reemplazar a la Unión Minera, había sido planeada para ser compartida por el Gobierno congolés y la Tanganyika Concessions en la siguiente proporción: $55 \%$ para el Gobierno congolés y $15 \%$ para Tanganyika Concessions, empresa que tenía participación similar en là antigua Unión Minera. El 30\% remanente pasaría a ser ofrecido a intereses privados extranjeros y congoleses. Se pensaba que el cobre sería vendido en el mismo Congo, en lugar de en Bélgica, y se nombró un Directorio provisional, consistente de cinco belgas, cuatro congoleses y un británico (Lord Colyton). Radio Kinshasa luego amplió la información:

"una vez que el $30 \%$ remanente disponible de la compañfa -que y'a ha sido ofrecido internacionalmente- haya sido absorbido, se completará el número de miembros de la Junta Administradora (Consejo de Administración). La Junta actual es provisional, pero será confirmada a partir del 18 de enero de 1967, con un mandato cle 5 años. El Congo, a pesar de ser accionista mayoritario, ofrece la presidencia del Consejo a un belga, como una forma de expresar el respeto que siempre ha profesado por la idea de una conjunta administración de intereses" ${ }^{\prime \prime}$.

La verdad es que los congoleses parecían abandonar su ritmo habitual con el fin de manifestarse amables para con los belgas. El embajador congolés en Bruselas, M. Mungo-Diaka, anunció en conferencia de prensa, el 28 de diciembre, que: los accionistas belgas pueden

solbid.

ribid. 
continuar con sus acciones, cargándolas al $30 \%$ señalado. En csto no hay problemas". Al ser preguntado si esto significaba que las acciones podian ser convertidas en intereses en la nueva empresa, replicó que "en principio, $5 i$ " 32 .

Sin embargo, esta actitud conciliadora ocultaba una fuerte posición negociadora. En su discurso ante el parlamento, el 24 de diciembre, Mobutu ya había delineado sus reclamos contra la Unión Minera. Esta había vendido clandestinamente cobre y otros minerales. Habia apoyado la política de M. Tshombe, y aun debía al Congo 4.000 millones de francos belgas por concepto de impuestos impagos correspondientes al periodo de secesión de Katanga. En seguida, Mobutu aseveró que la compañia le debía 7.500 millones de francos belgas (alrededor de $531 / 2$ millones de libras esterlinas) en impuestos correspondientes al cobre del pipeline entre el Congo y el mercado belga, suma esta última que insistió le debía ser cancelada antes del 15 de enero. También solicitó el pago correspondiente al $17 \%$ cle participación del Congo en el activo munclial de la Unión Minera, de un valor equivalente a 1.400 millones de francos belgas (alrededor de 10 millones de libras esterlinas).

Las posibilidacles de cooperación con los personeros belgas nombrados en el Consejo de la nueva compañía de Mobutu eran casi imposibles, luego que éstos se vieron enfrentados a las demandas señiladas anteriormente. Tampoco exa muy probable que Tanganyika Concessions formara parte del esquema clestinado a quebrar a la inmensa empresa belga, daclo que algunos de los clirectores de aquélla eran también directores de la Unión Mineria. Lord Colyton rehusó el nombramiento y, el 30 de diciembre, Tanganyika Concessions anunció que no se haría cargo del $15 \%$ de acciones que se le había ofreciclo de la nueva compañía. No podía ser, dijo, "parte en un acto ilegal de confiscación" ${ }^{\prime 3}$.

La negativa de Tanganyika Concessions a apoyar el proyecto congolés creó una nueva situación. En todo caso, la eventual aprobación de parte de aquélla no pasó, en el mejor de los casos, de constituir una leve esperanza. El Presidente Mobutu parecía haber quedado sin alternativas. Pero tenía que tomar una decisión rápidamente, puesto que las exportaciones de cobre estaban suspendidas descle el 24 de diciembre, hecho que estaba causando una crisis general en el Cintu-

rlbid.

stimes, 4 encro $196 \%$. 
rón Cuprero. Las tropas congolesas impedían la salida del cobre congolés del territorio nacional, lo que inevitablemente conducía también a una interrupción en el tráfico de cobre desde Zambia.

En estas circunstancias no cabía otra posibilidad que pasar de la "congolización" a algo más cerca de una nacionalización -aún cuando la diferencia entre ambos conceptos es muy sutil. El sábado 31 de di. ciembre, el Gobierno congolés decidió tomar a su cargo el activo de la Unión Minera en el Congo y formar una nueva compañia que lo controlara y en la cual el Congo sería propietario del $60 \%$ y tendría una mayoría de congoleses en el Directorio. La nueva compañía, Sociedad General Congolesa de Minerales o Gecomin, se haría efectiva a partir del 19 de enero de 1967 . E1 $40 \%$ restante sería colocado por suscripción pública.

Los dos vacios inmediatos en la nueva solución, como lo hiciera notar certeramente el corresponsal de Le Monde, estaban, en primer lugar, en el hecho que los 15.000 técnicos belgas esenciales para operar las minas, difícilmente iban a estar dispuestos a continuar trabajando para una empresa nacionalizada, con todos los riesgos que ello implica; y, en segundo lugar, el que el Congo se encontraría en una difícil situación financiera si la Unión Minera no pagaba su enorme deuda al gobierno al 15 de enero ${ }^{94}$. Dadas las circunstancias, la probabilidad de que lo hiciera era francamente remota. Por el contrario, la compañía belga confiaba en que el Congo se resentiria primero por la estrechez financiera.

Así las cosas, la Unión Minera aceptó la guerra. De inmediato amenazó con acción legal contra cualquier comprador de cobre katangués, y anunció al mismo tiempo que ésta era "el único dueño legal" de los productos producidos en sus propiedades en el Congo. Rechazó la demanda congolesa por 54 millones de libras esterlinas, pagaderas al 15 de enero por concepto de minerales ya exportados del pais, sosteniendo en cambio que el Gobierno del Congo le debía a la Unión Minera alrededor de 40.000 millones de francos belgas (alrededor de 280 millones de libras esterlinas) por concepto de equipos, inventarios y cuentas bancarias de su propiedad en el Congo, bienes que fueron traspasados a la nueva compañia ${ }^{35}$.

El editorialista financiero de The Times comentó que los intermediarios que operan en la Bolsa de Metales de Londres se mostraban escépticos acerca de la capacidad de la Unión Minera para disuadir a su clientela de comprar minerales de la compañía congolesa, enfrenro 1967 .

He Monde, 3 enero 1967.

wLa amenaza de la Unión Minera se publicó el 3 de enero. Detalles en Le Monde, 5 enc- 
tándolos a la perspectiva de una acción legal. Estas reclamaciones tienden a convertirse en procesos largos, en circunstancias que la industria no puede prescindir, mientras tanto, de sus abastecimientos de cobre y otros minerales" 36 . A pesar de la lógica de este argumento, la Unión Minera parecía dispuesta a llevar las cosas adelante, en el sentido indicado. Canceló el $17 \%$ de participación del Gobierno del Congo en las actividades de la Unión Minera fuera del Congo, sobre la base que los congoleses habían roto el acuerdo Spaak-Tshombe, de febrero de 1965. Luego ordenó a todos sus empleados belgas a retornar a Bélgica antes de fin de mes, so pena de ser despedidos en caso contrario.

Los congoleses, sin embargo, aún contaban con una buena carta en el bolsillo. Un vocero del gobierno señaló que sólo los países afiliados a la otan irían en ayuda de la Unión Minera, "y nada nos obliga a venderles nuestros minerales" 37 . Aclaró, además, que el acuerdo Spaak-Tshombe carecía de validez legal puesto que no habia sido ratificado ni por el Parlamento belga ni el congolés. Tampoco se podía aceptar la reclamación de la Unión Minera por compensaciones. De acuerdo a su información, la ley belga mediante la cual se había dado la concesión original a la Unión Minera en 1906 incluía una cláusula según la cual, luego de transcurridos 90 años, el activo total de la compañía volvła a manos del Estado. El Congo, dijo, reconoció esta ley en el momento de su independencia, pero ahora habia decidido poner fin a dicho acuerdo, luego de sesenta años de vigencia, en lugar de noventa. En consecuencia, agregó, el Estado congolés es el legítimo dueño de dos tercios del activo de la Unión Minera. Esta clase de argumento legal difícilmente podía impresionar a los directores de la Unión Minera, pero sin duda alguna que tenía cierto encanto.

El factor desconocido hasta el momento lo constituía la actitud del Gobierno belga. Durante la primera etapa de la crisis, en la última semana de 1966, aparecía como neutral, limitándose a expresar su deseo de ver respetados los acuerdos Tshombe-Spaak. Sin embargo, inmediatamente después del anuncio de nacionalización, el 31 de diciembre, el Ministro de Relaciones Exteriores de Bélgica dio a conocer una declaración en la que señalaba que "el Gobierno belga no puede identificarse con esta acción, ni en el plano legal ni en el polftico"38. Luego continuaba expresando que el Gobierno tomaría las medidas necesarias para salvaguardar los intereses belgas. Aun cuando en sí misma era una declaración inofensiva, sólo sirvió para exácerbar

soTimes, 4 cnero 1967.

TLe Mfonde, 6 enero 1967.

${ }^{2} L_{e}$ Monde, 3 enero 1967. 
los sentimientos congoleses y provocar una violenta reacción del Presidente Mobutu:

"Colocándose en abogado de una causa indefendible, el Gobierno belga demuestra una vez más que no controla ni a la Unión Minera ni a la Societé Généxale de Belgique, sino que, al contrario, rige la situación inversa"s9.

En todo caso, Mobutu no estaba exactamente en posición de enfrentar solo a la Unión Minera y al Gobierno belga. Había que hacer algunas concesiones. En todo caso, no cabe duda que el Gobierno belga debe haberse necesariamente preocupado con la idea de una prolongada cesación de embarques de cobre desde el Congo, que podría llevar a un cierre de la refinería de Hoboken en Bélgica, con el consiguiente golpe para la economía belga, aun cuando el pipeline de cobre era suficiente seguro contra este peligro, al menos por unas semanas.

El primer escollo en el camino lo constituía la fecha límite del 15 de enero. El Presidente Mobutu había reiterado su amenaza de hacerse cargo del total del activo de la Societé Générale de Belgique en el Congo, si para esa fecha la Unión Minera no había pagado sus deudas. Pero al mismo tiempo thabía sido conciliatorio, aun cuando en otro sentido, pues hizo referencia específica a la "congolización", en lugar de nacionalización, estableciendo que el Congo no se había hecho cargo del activo de la Unión Minera, sino que se había limitado a anular las concesiones de la compañía, como castigo por no haber trasladado las oficinas principales a Kinshasa.

Luego de frecuentes viajes entre Bruselas y Kinshasa, del embajador belga en el Congo, Mr. Paul Bihin, pareció que se había llegado a un principio de acuerdo. El Presidente Mobutu anunció que se desistiría de su decisión de tomar para su gobierno el activo de la Unión Minera, contentándose con la confiscación, a beneficio del Estado congolés, de la parte de la Unión Minera en unas trece compañfas operantes en el Congo. El valor de las mismas se estimó en alrededor de 40 mil millones de francos belgas ( 4.000 millones de francos franceses), una suma considerable si se piensa que Mobutu sólo había contemplado un reclamo por $71 / 2$ mil millones de francos belgas a la Unión Minera, por concepto valor del pipeline. A cambio de esto, Mobutu aseguraba que se mantendría la producción de cobre y la Unión Minera aceptó no insistir en la retirada de sus técnicos. Ambas partes acor-

${ }^{8}$ Le Monde, 5 enero 1967. 
daron que las respectivas reclamaciones de las partes opuestas serían sometidas a tribunales internacionales de conciliación, aun cuando se manifestaron cuudas acerca cle la utilidad de la Corte Internacional de La Haya, para estos efectos, ya que los Estados africanos habían demostrado poca confianza en dicho organismo, clespués del trastorno produciclo por la decisión de esa Corte en el asunto de Africa Sudoccidental, en julio de 1966. A pesar de toclo, Mobutu nombró a dos extranjeros para asesorar al Gobierno congolés en estas materias: a un abogaclo parisiense, Mr. René Floriot, y a uno norteamericano. Mr. Ted Sorensen, muy conocido como antiguo asesor clel Presidente Kennedy.

La presencia de Mr. Sorensen y M. Florior inevitablemente sirvió de estimulo a discusiones acerca de qué países o grupos se beneficiarian a raíz de la confrontación entre Mobutu y la Unión Minera. En círculos políticos de Bruselas había consenso acerca de la posición de Estados Unidos, a quien se veía como obligado a apoyar a Mobutu, aun cuando fuera para los solos efectos de impedir su caída, la que reviviria la posibilidad de que el Congo deviniera comunista. La radio de Moscú pensaba lo mismo, aun cuando su análisis tenía un sentido algo diferente. Un comentarista, Grigoriy Yefimov, decía:

"En mi opinión, los Estados Unidos están haciendo un doble juego en el Congo. El Gobierno de los Estados Unidos, como expresión de los intereses de los grandes capitales privados, está imposibilitado de apoyar la nacionalización de empresas privadas. Por otro lado, las medidas del Gobierno del Congo respecto de la Unión Minera socavan la influencia del principal competidor de Norteamérica en el Congo, vale decir, la influencia de Bélgica, lo que definitivamente gusta a los círculos financieros norteamericanos" 40 .

El periódico de Bruselas La Libre Belgique, en su edición del 17 le enero, expresó los temores de los círculos financieros belgas respeco a los franceses:

"Nosotros no queremos decir que Francia haya incitado al general Mobutu a tomar las insólitas medidas de las últimas semanas, pero dichas medidas han servido notablemente a los intereses franceses. En primer lugar, había que desalojar a los intereses belgas, cosa ya hecha o prácticamente hecha" $\$ 1$.

${ }^{0}{ }^{\prime} W^{\prime} B, 10$ Parte, La U.S.s.R., 26 enero 1967. "Citado en Le Monde, 18 enero 1967. 
El periódicó en cuestión agregaba luego que Francia, en el plazo de un año, no tendría dificultades en encontrar técnicos franceses, e incluso podría, probablemente, interesar personal tunecino, guineo o de otros países del área de influencia francesa. Pero,

"es esencial, sin embargo, que la Unión Minera permanezca intacta hasta el día que la toma sea posible. De ahí la razón por qué en Paris se ha deseado vivamente un acuerdo temporal entre el general Mobutu y la Unión Minera, a fin de salvar las instalaciones. $\mathrm{He}$ aqui el papel que le corresponde a la Bélgica de hoy: salvar el escenario para el sucesor de la Unión Minera".

y el diario terminaba:

"En la competencia internacional, la Francia lleva, Bélgica "no juega", los Estados Unidos no ven sino sus problemas presupuestarios y la guerra en el Vietnam".

Es difícil obtener evidencias acerca de la naturaleza exacta de la politica de Francia en esta coyuntura histórica, pero no cabe duda que los congoleses se felicitaban de cualquier síntoma de división en el frente europeo. En circunstancia de que habian fracasado en separax a Tanganyika Concessions de la Unión Minera, a fines de diciembre, cosa que por lo demás no sorprendió a nadie, al menos podian siempre abrigar la esperanza de que les fuera mejor con los franceses. En una entrevista, Mobutu declaró que "estarfamos muy contentos" si Francia rehusara participar en algún boycot internacional contra nosotros o nuestro cobre. Luego agregó con audacia, que sería característico de la política de De Gaulle el que Francia, en su deseo de ayudar a los débiles, en esta etapa hiciera algo por el Congo ${ }^{42}$.

La búsqueda de ayuda francesa constituyó un tema constante en la política congolesa a través de las semanas de la crisis, y las ideas exprezadas en La Libre Belgique se justificaron en parte al saberse que Mobutu nuevamente cambiaba su decisión anterior, anunciando que los técnicos belgas deblan dar aviso con un año de anticipación si deseaban marcharse del país. Si los belgas iban a ser reemplazados por franceses, y otros, se necesitaba tiempo para encontrarles reemplazantes.

El Gobierno belga protestó vigorosamente ante este nuevo hecho, sosteniendo que el acuerdo que había impedido la crisis del 15 de

${ }^{2}$ Le Monde, 20 enero 1967. 
enero no podría sostenerse en tales condiciones. La Unión Minera declaró que 1.000 técnicos habían expresado su deseo de abandonar el país, y que impedirles la salida era contrario a la declaración de los Derechos Humanos. Frente a esta oposición, Mobutu se retractó nuevamente. Sostuvo que no mantendría a los técnicos a la fuerza, pero señaló que disponía de fondos suficientes como para pagarles en la forma que estaban acostumbrados y que estimaba normal su petición de conceder tiempo al gobierno para encontrarles sucesores. También dijo que el Congo continuaría pagando 25 millones de francos belgas a Bélgica, correspondiente a la participación congolesa en la deuda externa contraída antes de la independencia.

Sin embargo, a pesar de estas obvias concesiones, el ánimo de Kinshasa era aún de un fiero nacionalismo. El 22 de enero, un africano disfrazado de sacerdote y que se suponía representaba a $M$. Louis Wallef, presidente de la Unión Minera, fue visto a la cabeza de una procesión en Kinshasa. Según el corresponsal de Agence France Presse, inmediatamente después de él iba un enorme ataúd, que contenía los restos mortales de lo que todos en el Congo llaman hoy la Unión Miseria. Las exequias de la Unión Minera tuvieron lugar en el mismo centro de Kinshasa, a 150 metros de la Embajada de Bélgica y en presencia del Presidente Mobutu y miembros del Gobierno ${ }^{43}$.

Después de este entierro ceremonial de la Unión Minera, a lines de enero resultaba obvio que la situación era irreversible. La nueva empresa congoleña constituía una realidad a la cual el resto debła adap. tarse. La gran interrogante continuaba siendo quịen se haría cargo de la comercialización del cobre y qué grupo tomaría el $40 \%$ de participación en la nueva compañía, ofrecido por el Gobierno congolés al capital internacional. ¿Qué grupo o consorcio financiero, nacional o internacional, se atrevería a desafiar el poder de la Unión Minera? La respuesta no tardó. Se informó que existía un grupo que pensaba en establecer un consorcio internacional que ocupara el lugar de la Unión Minera. Los sectores financieros mencionados eran la Banca Lambert, de Bruselas, y Peñarroya, de Francia (ambos ligados al grupo Rothschild), en Roan Selection Trust, empresa británica con grandes intereses en Zambia, y la Newmont Mining Corporation de los Estados Unidos ${ }^{44}$.

Inmediatamente que las anteriores informaciones fueron conocidas por los intereses tras la Unión Minera, éstos advirtieron que la Unión 
Minera emprendería acción judicial contra cualquier empresa que adquiriera interés en GECOMIN. Un comunicado conjunto de la Societé Générale de Belgique, Tanganyika Concessions y la Compañía Financiera cle Katanga, anunció lo siguiente:

"Los accionistas privados de la Unión Minera consideran que han sido objeto de confiscación. En consecuencia, estiman que todos aquellos que adquieran una participación en la Societé Générale Congolais des Minerais (GECOMIN), se asocian a esta expoliación. Frente a esta eventualidad están firmemente dispuestos a defender, de acuerdo con la Unión Minera, tanto sus derechos como sus intereses" 45 .

El grupo interesado en la formación de un nuevo consorcio internacional empezó instantáneamente a echar pie atrás. La American Newmont Mining Corporation negó que fuera a tomar parte en el consorcio. La Banca Lambert hizo saber que, en las actuales circunstancias, no tenía ningún interés en adquirir acciones de la compañía congolesa, y Peñarroya, a raíz de las discusiones habidas con sus eventuales socios, anunció:

"ésta estima, por su parte, que no debe tomar iniciativa alguna que tienda a contrariar la búsqueda de un arreglo entre las partes en disputa en el Congo-Kinshasa. En especial, no insiste en la idea de una suscripción de capital de la Générale Congolaise des Minerais (GECOMIN)" 4 .

La principal dificultad que enfrentaba el consorcio era que difícilmente podía tener esperanzas de operar frente a la oposición de la Unión Minera. Sin contar con la refinería belga de la Unión Minera. en Hoboken, la refinación del cobre congolés era prácticamente imposible, lo mismo que la comercialización si no se contaba con la enorme organización mundial de ventas de la compañía. De ahí que la Banca Lambert y los otros se vieran forzados a decir que sólo podrían optar al $40 \%$ de participaciones en CECOMIN con la condición de que la Unión Minera recibiera compensación adecuada y que, por tanto, pudiera entrar en el consorcio. "Ahora, si eso llega a suceder" señala The Economist, "¿quién necesitará a la Banca Lambert" 4 .

Tampoco era probable que Mobutu aceptara la vuelta de la Unión Minera al Congo, a no ser que dicho retorno fuera sutilmente disfrazado. En todo caso, se encontraba bajo indiscutidas presiones, es-

15Ibid.

¿Le Monde, 19 febrero 1967.

"Economist, 4 febrero 1967. 
pecialinente de su abogado norteamericano, Mr. Sorensen, para que aceptara la idea de compensar, al menos en principio. El New York Times informó que Mr. Sorensen había declarado haber aconsejado al Gobierno del Congo la negociación de algún tipo de pago a la Unión Minera ${ }^{48}$. De ahí que, mientras que en enero los congoleses tuviexon conversaciones a nivel de gobierno con los belgas, en febrero Mobutu se encontró nuevamente en conversaciones directas con la Unión Minera. A principiós de mes, tres personeros de la compañía viajaron de Bruselas a Kinshasa para conversaciones secretas; entre ellos se encontraban M. Jean Marie Dexriks, anterior representante de la Unión Minera en Kinshasa, y M. Henri Fortemps, anterior director-general de la compañia en Lumumbashi.

La naturaleza de su proposición al Gobierno congolés se filtró rápidamente. Se trataba de que la Unión Minera volviera a tener participación en los negocios congoleses, pero tras nueva organización, compuesta por la Compañía Marítima de Bélgica, la Sociedad Metalúrgica de Hoboken y la Sociedad General de Minerales de Bélgica. Estas tres empresas se encuentran estrechamente ligadas a la Unión Minera.

No podía ser muy sorprendente el que estas proposiciones fueran calificadas de "increíblemente negativas" por M. Jean Jacques Kandé, oficial de informaciones del Gobierno congolés ${ }^{49}$. Sin embargo, dado que se habían desvanecido las esperanzas de posible asistencia bajo la forma de un consorcio internacional organizado por la Banca Lambert, Mobutu no tenf́a alternativa, fuera de aceptar. Postergó un acuerdo, trató de obtener la ayuda de otros líderes africanos, renovó sus amenazas contra los técnicos belgas, pero todo en vano. De hecho, aun cuando la presencia en Kinshasa de los jefeś de Estado de seis pafses africanos, a mediados de febrero, dio la oportunidad a que Mobutu expresara su disconformidad ante la manera cómo el gobierno británico había manejado la crisis de Rodesia, sólo sirvió para postergar en algunos días su aceptación a las proposiciones de la Unión Minera. El 12 de febrero, Mobutu insistió ante los lideres africanos:

"rechazaremos vigorosamente toda solución que nos sea impuesta desde afuera y que sea conflictiva con los verdaderos intereses de Africa. La riqueza de Africa debe volver a los africanos, las riquezas sustraídas a los africanos deben serles devueltas, su tierra y derechos de prospección subterránea no podrán volver a ser violados, bajo ningún pretexto"so.

18Nav York Times (Edición curopen), 9 febrcro 1967.

"Le Monde, 7 febrero 1967.

soSWB, 4* Parte, 14 febrero 1967. 
Sin embargo, el 17 de febrero, cuando los jefes de Estado habían regresado a sús paises, Mobutu se entendió con la Unión Minera.

El acuerdo tomó la forma de una convención para cooperación técnica entre geCOMin y la Societé Générale des Minerais. Uno de los argumentos determinantes en la rendición de Mobutu fue la amenaza de la Unión Minera de llevarse con ella el mapa del subuelo de Katanga, clave indispensable para los depósitos mineros, y que se había confeccionado durante un período de 60 años. Una persona comprometida en estos acontecimientos gráficamente comentó: "es como si fuera a tomar posesión del Empire State Building sin disponer del plano de las cañerias y conductores de gas y electricidad" 51.

El resumen inicial del acuerdo, dado por Radio Kinshasa, fue el siguiente. (Para texto parcial del acuerdo, véase el Apéndice A):

"La Societé Générale des Minerais se compromete a proveer a GECDMIN una cantidad de servicios. Estos se refieren, en primer lugar, a los antecedentes sobre proyectos generales, necesarios para el adecuado funcionamiento de la compañía y su desarrollo, para empleo de personal, y para la administración minera, industrial y comercial de la empresa. Estos servicios comprenden también la ejecución de los programas diseñados por el Consejo administrativo de GECOMIN, el reclutamiento y puesta a disposición de GECOMIN de personal técnico no africano, necesario para el normal funcionamiento de la compañía y, finalmente, la comercialización de lo producido por GECOMIN"52.

Otras informaciones revelaron que el acuerdo tenía una vigencia de tres años. Se requiere de un aviso previo con 'dos años de anticipación para que cualquiera de las partes rompa el contrato.

¿Quién ganó? ¿Mobutu o la Unión Minera? La pregunta es importante, pues no sólo se trata de una transacción comercial inmediata, sino que de la entera afirmación internacional del régimen de Mobutu. El acuerdo fue motivo natural de controversia, tanto dentro como fuera del Congo. A primera vista se dan una serie de hechos difíciles de aceptar. La ISocieté Générale des Minerais (belga), que se haría cargo de la producción, procesamiento y comercialización del cobre, está controlada por la todopoderosa Societé Générale de Belgique, la empre-

Tle Monde, 14 febrero 1967.

asWB, 4" Parte, 20 febrero 1967. 
sa que maneja a la Unión Minera. Y esto no era todo. $\mathrm{El}$ inevitable y ubicuo $M$. Wallef también se encontraba en el directorio de la SGM. No se podía negar la lógica contenida en un telegrama recibido por Mobutu (y leído por él en conferencia de prensa), en el que decía que el acuerdo equivalía a robarle a Pedro para pagarle a Pablo, y que la expoliación belga consumiría al Congo hasta el tuétano de sus huesos ${ }^{53}$.

Por otro lado, analizado en términos de las limitadas demandas de Mobutu, el acuerdo puede ser calificado como éxito congolés. En los pesados días de enero era fácil olvidar que Mobutu nunca tuvo la intención de hacerse cargo total de la Unión Minera. Incluso cuando se vio forzado a actuar, a raíz de que la empresa rehusó transferir sus oficinas principales a Kinshasa, Mobutu prefirió hablar de "congolización" en lugar de nacionalización. Hay indicios, incluso, de que Mobutu nunca pensó más allá de Bélgica cuando se trataba de buscar capital extranjero para hacerse cargo del $40 \%$ de GECOMrn. De acuerdo con lo dicho por el propio Mobutu, la idea de formar un consorcio internacional nació de la Banca Lambert. En su conferencia de prensa el 21 de febrero, dijo:

"No fue el Gobierno congolés quien pensó en el Roan Selection Trust de Zambia, o Anglo-American, o Peñarroya de Francia. No señores, fue la Banca Lambert la de la idea. En lugar de presentarse sola, prefería asociarse con otros grupos, y le fue dado un poder para hacerlo"54.

De esta manera, si se recuerda que la campaña de Mobutu en contra de la Unión Minera se intensificó más bien accidentalmente, su triunfo de febrero no aparece tan hueco como creyeron algunos.

¿Quién estuvo contento con el acuerdo? El Gobierno congolés, obviamente. Radio Kinshasa anunció:

"mediante la firma de esta convención, la República Democrática del Congo, en ejercicio de sus derechos soberanos, ha tomado una. medida hacia el logro de la independencia económica del pafs, y restaura para sí todos los beneficios derivados de utilidades en moneda extranjera por concepto exportaciones de sus minerales" 55 .

Otros observadores satisfechos fueron los asesores en el Congo del Fondo Monetario Internacional, que respaldaron el acuerdo ${ }^{56} . E l$

ss SIY'B, 4" Parte, 23 febrero 1967.

ธl一bid.

xSW'B, 4* Parte, 20 febrero 1967.

soTimes, 18 tebrero 1967. 
ES T U D I O S I N T E R N A C I O N A L E S

New York Times pareció creer que Mobutu había triunfado y concluyó que "el inmediato resultado del acuerdo era la eliminación de la Unión Minera como factor determinante en la economía congole-

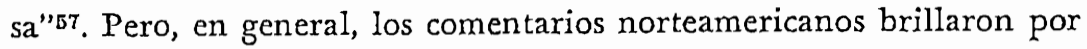
su ausencia.

La reacción del mundo comunista fue menos predecible que la de Occidente. Un comentario de Radio Moscú, a fines de enero, observó con cierta sorna que "el Gobierno del Congo había abandonado su intención original de confiscar la propiedad de la Societé Générale de Belgique. No cabe duda que esto se debe a presiones foráneas" 58 . A comienzos de febrero, criticó duramente el fracaso de la Banca Lambert y su consorcio para ayudar a Mobutu:

"el consorcio internacional creado por los monopolios occidentales para "ayudar" al Congo también sirve para avivar el fuego. Tratando de ejercer presión sobre Kinshasa, de hecho ha pedido la restauración de los derechos de la Unión Minera" „øø.

Luego del acuerdo del 17 de febrero, Pravda proclamó la victoria de Mobutu:

"El acuerdo demuestra que las potencias occidentales sufrieron una desilusión en sus esperanzas de que Mobutu no fuera capaz de soportar una "guerra de nervios" con la Unión Minera" 60.

Casi inmediatamente clespués, un comentario de la Radio Paz y Progrcso, de la Unión Soviética, intentó explicar a sus oyentes africanos que los regimenes militares en Africa no estaban desprovistos de ciertos aspectos positivos:

“En muchos países africanos las fuerzas armadas no son instrumento del imperialismo y de la reacción local. Los representantes progresistas de las fuerzas armadas en un gran número de países africanos juegan un papel positivo en la resolución del destino histórico de sus pueblos. Los oficiales y soldados de mentalidad patriótica ven las consecuencias nezativas de la dominación colonial. Esta es la razón por qué las fuerzas armadas de ciertos países africanos se unen a todas las fuerzas progresistas de la nación para afirmar su inde-

${ }^{87}$ New York Times, 18-19 febrero 1967.

ws SW' $B$, 10 Parte, 26 febrero 1967.

sopravda, artículo de Igor Bclyayev, citado en $S W B, 1$, Parte, 3 febrero 1967.

OPravda, artículo por M. Zenovich, citado en SIVB, 10 Parte, 23 febrero 1967.

$$
\left[\begin{array}{lll}
4 & 8 & 2
\end{array}\right]
$$


pendencia política y económica y resguardar los intereses del pueblo"'1.

Esta tendencia del pensamiento comunista orientado por Moscú acerca de Africa en general y del Congo en particular se observa aún más definida en un comentario de la Radio Praga, de mediados de marzo. Al comentar el acuerdo de febrero, el locutor dijo:

"los términos son más bien rentajosos para el Congo y el compromiso fue un éxito para el gobierno del general Mobutu, aunque háy que admitir que con reservas. El general turo éxito al dejar bajo control la influencia belga en el Congo, y no cabe duda que este es un paso importante en el camino hacia la emancipación económica del Congo"'62.

Este sorprendente comentario pro Mobutu continuó criticando implícitamente a Lumumba cuyo "programa en sí mismo no estaba en armonía con las posibilidades concretas de su tiempo" y alabando a Mobutu indirectamente, a través de su pragmatismo y realismo. A la luz de lo anterior no resulta tan extraordinario que dos guerrilleros congoleses declararan a la Agencia de Noticias Nueva China, en El Cairo, que el pueblo congolés luchará hasta lograr la completa independencia, "cualesquiera que sean los trucos usados por los imperialistas norteamericanos y los modernos revisionistas soviéticos para sostener el régimen títere cle Mobutu"63.

De hecho, el Congo a esta fecha se había transformado en otro elemento en la disputa chino-soviética sobre asuntos mundiales. Los grupos pro-chinos (especialmente el Partido Comunista belga pro chino y la Organización de Solidaridad de los Pueblos Afro-Asiáticos-Latinoàmericanos, de origen cubano) se colocaron sólidamente tras el remanente del movimiento guerrillero de Pierre Mulele. Un comunicado de la AALAPSO, en febrero, en el aniversario de la muerte de Lumumba, describía como "Mobutu, uno de los asesinos de Lumumba, invoca el nombre de nuestro héroe nacional, en forma cínica y carente de vergüenza, con el objeto de llevar adelante su política neocolonialista, disfrazada de nacionalismo" 04 .

La radio de Praga explicaba lo anterior:

"sin embargo, la verdad es que, al hacerse cargo del mensaje de este héroe nacional era la única forma de sacar al Congo del caos de la

a1SW'B, 10 Parte, 24 febrero 1967.

02Charla de Vera Stovickeva. el 15 marzo, $S W^{\prime} B$, 24 Parte, Europa Oriental, 21 marzo 1967. mSWB, 3s Parte, El Lejano Oriente, 18 enero 1967.

mSIV $B$, th Parte, 14 febrero 1967. 
guerra civil. Las fuerzas patrióticas se vieron súbitamente enfrentadas al hecho de que el Gobierno Central congolés, contra el cual ellos habían luchado, demostraba lealtad, no sólo en palabras, sino en los hechos, hacia un hombre por cuyos ideales habían estado dispuestos a morir"65.

Continuó informando que gran número de guerrilleros se habían entregado y expresado el deseo de apoyar al Gobierno Central, concluyendo que "sin duda, este es uno de los triunfos menos espectaculares del general Mobutu, pero de extremada importancia en lo que se refiere a su política interna". (Para consultnr el texto de.comentarios clinos, véase Apéndice $B$ ).

Las diferencias chino-soviéticas alrededor del Congo son sólo periféricas a la historia de la consolidación de Mobutu en el poder, aun cuando es significativo que el punto de vista soviético coincicla tan de cerca con el de los Estados Uniclos. Más directo, sin embargo, en relación al futuro mismo del Congo, es el papel por desempeñar de Francia. Anteriormente ya se sugirió que Mobutu habría demostrado un interés poco usual en tratar de asociarse a los franceses en planes que lo hubieran sacado de sus dificultades. En febrero, esto pareció dar resultados. El 23 de febrero, se informó que el Ministro de Relaciones Exteriores, M. Bomboko, luego de una visita a París, obtuvo un crédito a corto plazo de 100 millones de francos franceses, para cubrir la suma que el Congo había dejado de recibir durante enero y febrero, debido a la suspensión de las exportaciones de cobre y cobalto ${ }^{86}$. Las observaciones de M. Bomboko sobre Francia fueron muy halagadoras:

"Para el Congo, país en vías de desarrollo, Francia es, de todos los países industrializados, el que está en mejores condiciones de aportar ayuda eficaz e inmediata" 67 .

Detrás de las palabras suaves, el hecho concreto es que Gecomin, Ia empresa congolesa, no ha encontrado a nadie que quisiera tomar el $40 \%$ de participación en la misma, ofrecida al mercado. Bomboko re-

Wćase nota 62.

esw'B, 40 Parte, 25 febrero 1967.

"Le Mondc, 19-20 febrero 1967. En un artículo aparecido en The Nalion, 6 de marzo 1967, litulado "Proxy Fight in the Congo", Paul Semonin señala que "los compradores francescs de cobre congoleño aumentaron en forma espectacular durante los primeros seis meses de 1966, hasta que Francia se estima llegó a comprat un 40\% del cobre congoleño". 
cordó a los franceses que, paralelamente al acuerdo del 17 de febrero, continuaban las negociaciones entre las autoridades congolesas y el consorcio internacional, entre los cuales proseguía figurando Peñarroya. Si los franceses no venían en su auxilio, existía el peligro -indiscutiblemente posible- de que, tal como lo sugiriera El Economist, reapareciera la Unión Minera para hacerse cargo de la fracción no poco importante, $40 \%$ de la empresa congolesa ${ }^{68}$. Para impedir esto, GECOMIN dio plazo hasta fines de marzo al grupo Lambert para formar su consorcio internacional, $y$ en caso de fallar éste, GECOMIN planeaba organizar una suscripción pública de las acciones disponibles.

Durante el año y medio que Mobutu ha estado en el poder en el Congo, Africa ha visto muchos cambios. No menos de otros ocho países han cafdo bajo gobiernos militares durante este período. Sin embargo, sería un error el permitir que tantos y tan variados cambios en el continente visto en su totalidad nos cieguen respecto de lo que ha ocurrido en el Congo, país que sigue sienco uno de los pocos países africanos de verdadera importancia internacional, debido a su tamaño, recursos y posición geográfica. El general Mobutu ha traido estabilidad al Congo. Al respecto no hay dudas. Ha eliminado la oposición, atacado el problema del tribalismo, dañado el poder de intereses económico-financieros otrora gigantescos, restablecido la influencia de su país en el concierto de países africanos, y ha unificado a la Unión Soviética y a los Estados Unidos en su apoyo. Es un historial notable, y que promete ulteriores años de estabilidad para el Congo. El problema está en si acaso los congoleses no se preguntarán en las próximas décadas - como tal vez se lo pregunten los habitantes de la España de Franco o el Portugal de Salazar- si acaso basta con la estabilidad.

\section{ApÉNDICE A}

El acuerdo entre GECOMIN y la Societé Générale des Minerais.

El siguiente texto parcial se deriva de aquel lefdo por el Presidente Mobutu en conferencia de prensa, en Kinshasa, el 21 de Lebrero de 1967, transcrito y traducido por el servicio correspondiente de la BBC de Londres. Algunas partes están incompletas y no puede haber garantía de su exactitud. (Referencia: BBC,

Economist, 25 febrero 1967. 
Resumen de Emisiones Mundiales de Radiofonía, Parte 4ạ, El Medio Oriente y Africa, 23 de febrero, 1967) .

Convención para Cooperación Técnica entre la Compañía Congolesa de Minerales de Kinshasa, de ahoril en adelante clenominada GEComin y representada por su Presidente, Mr. Jean Batiste Kibwe, y su Administrador, Mr Rodolphe Yav, y la Sociedad General de Minerales, compañía limitada de Bruselas, de aquí en adelante denominada SGM representada por M. Henri Fortemps, ingeniero de minas, y M. Joseph Derrick, ingeniero de minas, todos debidamente autorizados para actuar. Se acuerda lo siguiente:

\section{Articulo 19}

En virtud de esta Convención, sGM sc compromete a proveer a GECOMIN, quien acepta, una serie de servicios en relación a:

a) el estudio de proyectos generales requeridos para administrar convenientemente las instalaciones $y$ desarrollarlas, para el empleo de personal y para la administración mincra, industrial y comercial de la empresa;

b) la ejecución de los programas diseñados por la administración de GECONIN;

c) el eclutamiento y la facilitación a Geconin de personal técnico no africano, necesario para el normal desenvolvimiento de la empresa;

d) refinación, procesamiento para la entrega definitiva al mercado, $y$ comercialización.

Arliculo 20

El estudio de los programas generales a realizarse en virtud del artículo 19 , anterior, son confiados por GECOMIN a sGM. Esta última entregará al Directorio de GECOMIN el resultado de sus estudios. El Directorio de GECOMIN confía a sGM la ejecución del programa, y esta última toma a su cargo la administración de las operaciones industriales y comerciales.

\section{Articulo 3?}

Con el objeto de asegurar la comercialización de la producción en las mejores condiciones posibles, sGM $)^{\prime}$ GECOMIN acuerdan un programa de comercialización que tome en cuenta las demandas impuestas por la producción, las tendencias generales de la comercialización y la necesidad de remitir divisas al Congo tan pronto ello sea posible.

\section{Articulo $4 \div$}

Dentro de sus disponibilidades, sgm pone de inmediato a disposición de cecomin el personal no africano necesario para asegurar las operaciones normales de la empresa. Este personal firmará con sGm un contrato de asistencia técnica en el extranjero. Dicho contrato formará parte integral del contrato mediante el cual dicho personal es transferido a GEComin. Gecomin pagará a este personal. Los pagos en virtud de contratos de asistencia técnica se harán a través de sGM. El personal no africano de empresas afiliadas que trabajen en el Congo tendrá un status semejante al del personal de GeComin. Lo anterior se refiere al personal no africano de las subsidiarias de la antigua Unión Minera, que ahora pasaron a ser empresas congolesas. El personal de asistencia técnica ocupará los alojamientos que se les había 
asignado antes del 31 de diciembre de 1966; lo mismo se hace extensivo a colegios y otras instalaciones. GEcomin se compromete a mantener en su forma actual los servicios médicos y de enfermería, en orden a garantizar al personal la continuidad de las facilidades vigentes anteriormente.

\section{Articulo 59}

En la medida que las indicaciones anteriores no puedan ser realizadas por el personal de Gecomin en el Congo, sea en su totalidad o en parte, scar se compromete a poner a disposición de GeCOMIN los fondos necesarios (palabras ininteligibles), así como el reclutamiento y administración de personal, servicios de compra y transporte de toda clase de abastecimientos por cuenta de cecomrs, las cantidades necesarias para el desarro. llo y abastecimiento de sus (... ¿empresas?), ingeniería civil y planificación industrial y metalúrgica, así como promoción de sus metales.

\section{Artículo 69}

SGM venderá, por cuenta de GECOMIN el cobre $y$ otros metales y minerales producidos -en la medida que sGM esté en condiciones de asegurar su comercialización, considerando la situación del mercado y la capacidad del mercado para absorber dicha producción (ininteligibles los detalles sobre comercialización).
Artículo 79

GECOMIN asegura los valores de sGM con el objeto de proveer a sGM de las garantías necesarias en relación a sus obligaciones hacia el personal empleado en virtud de contratos de asistencia técnica.

Artículos 89 y 99

(aspectos financieros -ininteligibles).

Artículo 10.

A no ser que lo contrario aparezca indicado en protocolo anexo, todas las discrepancias, de cualquier naturaleza, que se originen entre Gecom por un lado, y sGir por el otro, respecto a diferencias de interpretación o de ejecución de la presentc Convención, serán dirimidas mediante arbitraje. (Detalles sobre procedimiento del arbitraje).

\section{Artículo 11.}

La presente Convención serí de vi. gencia ilimitada. Cada una de las partes puede darla por terminada con clos años de aviso previo. Hay cuatro copias de esta Convención y de sus protocolos. La primera para los archivos de la República Democrática del Congo, la segunda para el Banco Nacional del Congo, la tercera para geconris y la cuarta para sGir. Las cuatro copias se encuentran certilicadas.

Concluido en Kinshasa, el 15 de febrero, 1967.

\section{Apéndice B}

Informe sobre las Operaciones de los rebeldes del Congo (Kinshasa). NCNA en inglés, 20.21 GMT 14.4.67.
Texto del despacho desde Pekín, 14 de abril de 1967:

Las fuerzas patrióticas del Congo 
(L), continuando persistentemente en la correcta orientación de obtener una real independencia nacional a través de la lucha armada, han aprendido a pelear durante el curso de la guerra. Han sumado constantemente sus experiencias y continúan en su avance para obtener nuevas victorias.

Las llamaradas de la lucha armada del pueblo congolés ( $L$ ) contra el imperialismo norteamericano y sus lacayos, fueron estimuladas por las fuerzas armadas patrióticas, dirigidas por Pierre Mulele en la región de Kwilu, en la parte occidental del Congo (L), a comienzos de 1964. Posteriormente, las rugientes llamaradas de esta guerra justa se extendieron gradualmente hacia las regiones oriental y nororiental del pais.

El imperialismo yanqui y sus títeres han puesto en práctica, durante más de tres años, una política de "envolvimiento y supresión" de estas fuerzas armadas populares. Han recurrido a toda clase de tácticas siniestras y brutales, incluyendo el envío de "fuerzas de las Naciones Unidas", controladas por los norteamericanos, para llevar a cabo la supresión, la agresión directa por tropas norteamericanas en colaboración con fuerzas belgas y británicas, el "envolvimiento y supresión" por el régimen títere de Mobutu, y además, verdaderas carnicerías por parte de los más salvajes mercenarios blancos, reclutados en el extranjero.

El imperialismo yanqui ha trabajado mano a mano con los modernos revisionistas soviéticos para llevar a cabo el plan político de dividir, desintegrar o comprar a las fuerzas armadas patriotas. Pero hoy, la primexa $y$ antigua base establecida on
Kwilu permanece intacta y las fuerzas patrióticas se demuestran activas en las vastas áreas rurales y boscosas, infligiendo conscantemente duros golpes al enemigo y saliendo aún más fuertes en la lucha.

En el transcurso de intensos combates, los guerrilleros congoleses han prestado atención al estudio de los grandes conceptos del Presidente Mao acerca de la guerra de los pueblos. Mediante la constante suma de experiencias han adoptado tácticas más flexibles para golpear al enemigo. Han efectuado muchos ataques por sorpresa, emboscadas, destruido vías férreas, caminos y puentes para eliminar efectivos de las tropas títeres.

En el frente occidental, región de Kwilu, las áreas bajo el control de las fuerzas patrióticas dirigidas por Mulele se expanden constantemente, a pesar del cruel "envolvimiento y supresión" llevado a cabo por el régimen títere con sus fuerzas de choque. Las guerrillas han ampliado su esfera de acción mucho más allá del área triangular de Kikwit-Idiofa-Sangu, del área base establecida al comienzo de la lucha armada para alcanzar el río Kasai, de las áreas cerca de Puerto Francqui y bien al interior de la Provincia de Kwango.

En la región del frente oriental, las fuerzas armadas patrióticas han dominado las costas del lago Tanganyika y han forzado la retirada de las tropas títeres de un sinnúmero de lugares. En la región del frente nororiental miles de guerrilleros han persistido luchando en una serie de áreas. De resultas de sus ataques han sido inutilizados muchos caminos, los que ya no podrán ser usados por el. régimen titere.

Las fuerzas armadas patrióticas del 
Congo han seguido adelante con la idea de establecer y consolidar áreas bases en las zonas rurales. Estas fuerzas armadas patrióticas, que hacen toda clase de esfuerzos para construir y consolidar estas áreas bases, han establecido organizaciones administrativas, centros de entrenamientos militares y escuelas en el área base de Kwilu. Con el objeto de reducir la carga que representan para el pueblo de esas áreas, reclaman tierras incultivadas, crian ganado, pescan, y establecen un nuevo tipo de aldeas en la floresta. Recientemente le han hecho una seria advertencia al imperialismo norteamericano y a sus Iacayos en el sentido que "nuestro Congo es un vasto territorio de grandes e impenetrables bosques, que permitirán a nuestras guerrillas luchar durante 100 años".

El Presidente Mao ha dicho: "la guerra revolucionaria es una guerra de las masas, puede impulsarse sólo movilizando a las masas y confiando en ellas". Las fuerzas armadas patrióticas congolesas han logrado un creciente y éfectivo apoyo del pueblo revolucionario. Numerosos aldeanos han ayudado a los guerrilleros con alimentos e información acerca de movimientos de las tropas títeres. Organizaciones secretas revolucionarias, tales como los comités políticos, sociales y de propaganda han sido es- tablecidos aun en aldeas pequeñisimas. Gracias a la ayuda del pueblo, las guerrillas han establecido comités políticos en los "centros de recepción" del enemigo (similares a los caserlos estratégicos establecidos por los Estados Unidos en el Vietnam del Sur). La tarea de estos comités políticos es la de organizar a las masas para que apoyen la lucha patriotica.

Para golpear más efectivamente al enemigo, las fuerzas armadas patrioticas han realizado recientemente un profundo análisis de su experiencia y han sacado lecciones de sus operaciones; han consolidado sus filas $y$ unificado su pensamiento. Habiendo hecho esto, su orientación es más clara y su confianza mayor.

El periódico congolés Revolución informó en octubre del año pasado que, habiendo analizado su experiencia, el cuerpo dirigente de las fuerzas armadas patrióticas llegó a la conclusión de que la situación de la lucha armada es excelente. El grueso de la masa del pueblo está siendo organizada en una escala extensiva y están decididos a hacer sacrificios para la liberación de su patria. El pueblo congolés sabe muy bien que la revolución siempre sigue un camino tortuoso y zigzagueante. Pero el futuro es brillante y la victoria final llegará irremediablemente. 